\title{
Das höhere Schulwesen im Kursachsen des 18. Jahrhunderts und die dort vermittelten Unterrichtsinhalte
}

\author{
von \\ DETLEF DÖRING
}

Sachsen gilt neben Württemberg als ein Land, das in der Geschichte des deutschen Schulwesens einen herausragenden Platz einnimmt, nicht zuletzt in der Epoche der Frühen Neuzeit. In einem auffälligen Kontrast zu jener Beobachtung befindet sich der nur als mangelhaft zu bezeichnende Stand der wissenschaftlichen Erschließung dieses Themas, ${ }^{1}$ wenn auch durch eine jüngsthin erschienene umfangreiche Untersuchung ein wesentlicher Schritt zur Verbesserung der Forschungslage geleistet worden ist. ${ }^{2}$ Was jedoch auch weiterhin fehlt und eine entscheidende Voraussetzung für eine hoffentlich einmal $\mathrm{zu}$ erwartende Gesamtdarstellung bildet, das sind Untersuchungen zu konkreten einzelnen Schulen. Solche zugegebenermaßen nur schwer zu entwerfenden Darstellungen des schulischen Alltags sind gegenwärtig fast gänzlich zu vermissen, zumindest was Arbeiten jüngeren Datums angeht. ${ }^{3}$ Nur auf der Grundlage eines solchen Wissens könnten wir

1 Eine zusammenfassende Darstellung zum höheren Schulwesen im 18. Jahrhundert bietet: Jens BRUnING, Das protestantische Gelehrtenschulwesen im 18. Jahrhundert: Pietismus - Aufklärung - Neuhumanismus, in: Notker Hammerstein/Ulrich Herrmann (Hg.), Handbuch der deutschen Bildungsgeschichte, Bd. II: 18. Jahrhundert, München 2005, S. 278-323. Das Schulwesen in Sachsen wird dort allerdings im Vergleich zu den anderen Territorien des Reiches denkbar knapp abgehandelt (eine knappe Seite gegenüber vier Seiten zu Brandenburg-Preußen). Mit einiger Berechtigung verweist Bruning jedoch auf den soeben monierten schlechten Forschungsstand. Über die Schilderung der engeren Wolfenbütteler Schulgeschichte hinaus geht folgender Ausstellungskatalog: Glaubenslehre, Bildung, Qualifikation. 450 Jahre Große Schule in Wolfenbüttel, Berlin 1993. Der Band bietet breiteres Informationsmaterial vor allem zur Schulwirklichkeit des 17. Jahrhunderts. Eine knappe Überblicksdarstellung bietet Magret Kraul, Das deutsche Gymnasium 1780-1980, Frankfurt a. M. 1984.

2 Vgl. Thomas Töpfer, Die „Freyheit“ der Kinder. Territoriale Politik, Schule und Bildungsvermittlung in der vormodernen Stadtgesellschaft. Das Kurfürstentum und Königreich Sachsen 1600-1815, Stuttgart 2012. Das Schwergewicht der Arbeit liegt allerdings beim Volksschulwesen.

3 Wertvolles, keineswegs hinreichend ausgeschöpftes Quellenmaterial bieten die Programme der einzelnen Schulen, die im 19. und noch zu Beginn des 20. Jahrhunderts jährlich veröffentlicht worden sind. Die Geschichte der eigenen Einrichtung gehörte zu den bevorzugten Themen. Einen Erkenntnisgewinn würde auch die Beschäftigung mit den alten Schulbibliotheken, soweit noch erhalten, erbringen. Immer noch von Nutzen ist ein 1961 erschienener Sammelband über ausgewählte sächsische Gymnasien: Aus der 
jedoch die tatsächliche Schulwirklichkeit in den Blick bekommen und wären nicht mehr, wie gegenwärtig, zu einseitig auf die bloße Analyse obrigkeitlicher Verordnungen und die Lektüre pädagogischer Programmschriften angewiesen. Beide Textsorten sind in ihrem Aussagegehalt bzw. Wahrheitsgehalt bekanntlich nicht unproblematisch. Ich kann im Folgenden nur den Versuch unternehmen, auf Grundlage der mir verfügbaren, aus subjektiven und objektiven Gründen begrenzten und daher am Ende eher zufälligen Quellenkenntnisse einige wenige, vielleicht aber dennoch aufschlussreiche Schlaglichter auf das Schulleben des 17. und 18. Jahrhunderts zu werfen, wobei ich mich auf die dort vermittelten Lehrinhalte konzentrieren will.

Von grundlegender Bedeutung für die Entwicklung des höheren Schulwesens in Sachsen war das 16. Jahrhundert. ${ }^{4}$ Schulen gab es schon lange zuvor, aber der Beginn der Frühen Neuzeit bedeutete doch auch hier in vielerlei Hinsicht einen neuen Anfang. In seiner damals gewonnenen und über die Jahrhunderte sich nur zögernd verändernden Gestalt ist das Schulwesen in den protestantischen Territorien ein Ergebnis des Zusammenwirkens von Humanismus, Reformation und landesherrlichem Reglement. Die in Deutschland in der Mitte des 15. Jahrhunderts in breiterer Front einsetzende Bildungsbewegung des Humanismus hatte die Hinwendung zur Antike, d. h. vor allem zur Sprache und Literatur der Römer und Griechen in das Zentrum ihrer Bestrebungen gestellt. Auf Jahrhunderte hinaus bildete die Vermittlung entsprechender passiver, vor allem aber auch aktiver Sprachkenntnisse das Hauptziel der höheren Schulausbildung. Dabei ging es weniger um eine selbstständige Aneignung des Lesestoffs, dessen Sachinhalte im Unterricht eine eher untergeordnete Rolle spielten, sondern um die bloße Imitation. Der Schüler sollte befähigt werden, z. B. im Latein Ciceros zu schreiben und möglichst auch zu sprechen. Der Humanismus beherrschte aber schon wenig später nicht mehr allein das Feld. Er wurde, und das ist vor allem das Werk Philipp Melanchthons, in die große Erneuerungsbewegung des christlichen Glaubens integriert, die von Wittenberg aus ihren Anfang nahm. Die humanistische Bildung sollte nach deren Vorstellung nicht um ihrer selbst willen vermittelt werden, sondern hatte im Dienste der Erziehung zum rechtgläubigen und damit

Geschichte bedeutender Schulen Mitteldeutschlands, Bd. 1: Sächsische Gymnasien, Troisdorf vor Bonn 1961. Ergänzend ist heranzuziehen: Aus der Geschichte bedeutender Schulen Mitteldeutschlands, Bd. 2: Gymnasien der Provinz Sachsen und des Landes Anhalt, Troisdorf vor Bonn 1966. Dort werden mehrere Schulen behandelt, die im 18. Jahrhundert zu Kursachsen gehörten. Das Beispiel einer modernen Darstellung der Geschichte einer einzelnen Schule bietet: Joachim Castan, Hochschulwesen und reformierte Konfessionalisierung. Das Gymnasium Illustre des Fürstentums Anhalt in Zerbst, 1582-1652, Halle 1999.

4 Vgl. Heinz-Werner Wollersheim, Philipp Melanchthon und die Organisation des protestantischen Schulwesens in Sachsen, in: Philipp Melanchthon und das städtische Schulwesen, Halle 1997, S. 49-80. Ulrike Ludwig, Das mitteldeutsche Bildungswesen vom Schmalkaldischen Krieg bis zum Ende des Dreißigjährigen Krieges - Ein Überblick, in: Detlef Döring/Cecilie Hollberg (Hg.), Erleuchtung der Welt. Sachsen und der Beginn der modernen Wissenschaften. Essays, Dresden 2009, S. 64-71. 
einhergehend tugendhaften Christen zu stehen. Das bildete den zweiten Hauptinhalt des schulischen Unterrichts. Der Landesherr schließlich verfolgte als Ziel den immer dichteren Ausbau der Verwaltung seines Territoriums. Dazu benötigte er ein Personal mit entsprechender Ausbildung. Das wiederum erforderte die Gründung von Schulen, die in der Lage waren, ein entsprechendes Wissen und Können zu vermitteln. Im albertinischen Sachsen hat man dem in einem vorbildlichen Maße durch die Errichtung der drei Fürstenschulen Pforte, Grimma und Meißen Rechnung getragen. ${ }^{5}$ Von deren Absolventen wurde erwartet, dass sie eine Universität, möglichst eine der beiden Landeshochschulen Leipzig und Wittenberg, besuchen würden. Der an den Fürstenschulen vermittelte Unterricht besaß ein höheres Niveau, als es an normalen Gymnasien gemeinhin geboten wurde. Dementsprechend ausgeprägt war das Elitebewusstsein unter ihren Abgängern entwickelt. Die notwendigen nicht unerheblichen materiellen Voraussetzungen für diese Schulgründungen boten die Säkularisationen, die im Gefolge der Reformation umfangreiches Kirchengut in die Hand der Landesfürsten brachten. So konnten alle drei genannten Schulen in ehemaligen weitläufigen Klosteranlagen untergebracht werden. Bei der Wahl der Lehrer vermochte man in der Hauptsache auf die wachsende Zahl der Absolventen der Wittenberger, eben von Melanchthon geprägten Hochschule zurückzugreifen. Die großzügige Vergabe von landesherrlich finanzierten Stipendienplätzen an diesen Schulen ermöglichte schließlich auch begabten Kindern vermögensschwacher Familien den Schulbesuch.

Auch in dem uns vor allem interessierenden 18. Jahrhundert nahmen die Fürstenschulen immer noch unangefochten die Spitzenposition im sächsischen Schulsystem ein. Ihnen folgten an zweiter Stelle die nicht selten auf spätmittelalterliche Anfänge zurückgehenden „normalen“ Lateinschulen ${ }^{6}$ in den großen und kleinen

5 Vgl. Jonas Flöter/Günther Wartenberg (Hg.), Die sächsischen Fürsten- und Landesschulen. Interaktion von lutherisch-humanistischem Erziehungsideal und ElitenBildung, Leipzig 2004 (nur zwei Beiträge zur Geschichte der sächsischen Fürstenschulen in der Frühen Neuzeit). Immer noch nützlich ist: O. HeIne, Fürstenschulen, in: Encyklopädisches Handbuch der Pädagogik, 2. Bd., Langensalza 1896, S. 486-496. Winfried MüLler, Herzog Moritz und die Neugestaltung des Bildungswesens nach der Einführung der Reformation im albertinischen Sachsen, in: Karlheinz Blaschke (Hg.), Moritz von Sachsen - Ein Fürst der Reformationszeit zwischen Territorium und Reich, Leipzig/Stuttgart 2007, S. 173-201. Zu den einzelnen Fürstenschulen liegt neuere Literatur vor, die jedoch einen mehr oder minder populären Charakter besitzt, z. B. Hans Heumann, Schulpforta. Tradition und Wandel einer Eliteschule, Erfurt 1994. Von der kurfürstlichen Landesschule zum Gymnasium St. Augustin zu Grimma 1550 2000, Beucha 2000. Umfangreiche Literaturangaben vermittelt: Petra Dorfmüller, Leben und Werke der Rektoren der Landesschule Pforta von 1543 bis 1935, Beucha 2006.

6 Lateinschule ist nur eine der anzutreffenden Bezeichnungen dieser Schulen, daneben war auch manch andere im Gebrauch: Gymnasium, Gymnasium illustre, Lyzeum, Athenäum, Große Schule, Trivialschule, Pädagogicum. Die Bezeichnung einer Schule konnte auch zu Kontroversen zwischen den Verantwortlichen führen. So kommt es in Lauban zum Streit zwischen dem Pfarrer und dem Schulrektor, der seine Einrichtung in „Minervum“ umwandeln will. Vgl. Universitätsbibliothek Leipzig, Ms 0307 (II), Bl. 179-228 (ausführliche Dokumentation dieser Diskussion). 
Städten des Landes. ${ }^{7}$ Diese boten in ihrer Gesamtheit ein recht differenziertes Bild. Das gilt schon für die einzelnen Schulen selbst. Der dort vermittelte Wissensstoff konnte sich von Elementarkenntnissen bis zu einem hochschulähnlichen Inhalt spannen. So wird über die unterste Klasse der durchaus angesehenen Laubaner Lateinschule vermeldet, dass dort Knaben verschiedener Art unterrichtet wurden. Dem Lehrer sei es daher nicht möglich gewesen, sich nach eines jeden Unwissenheit in den Anfängen der Lateinischen Sprache zu richten. Man wird vermuten dürfen, dass das in der untersten Klasse vermittelte Wissen nur bescheidenen Ansprüchen gerecht werden konnte, gleichwohl aber für viele Schüler als durchaus ausreichend für die später zu erwartende berufliche Tätigkeit angesehen wurde. Wer in die höheren Klassen aufsteigen wollte, der musste sich anderweitig die nötigen Sprachkenntnisse aneignen. Der spätere Leipziger Professor Johann Heinrich Winkler, dem wir glaubwürdige Nachrichten über die Laubaner Schulverhältnisse zu Beginn des 18. Jahrhunderts verdanken, nahm daher Nachhilfeunterricht bei einem Primaner und konnte so die nächste Klasse erreichen. Andererseits erteilte der Rektor am Sonntag für ausgesuchte Schüler einen speziellen Unterricht, der, so Winklers Urteil, fast dem Universitätsniveau entsprach. ${ }^{8}$

Deutliche Unterschiede sind aber auch zwischen den einzelnen Schulen anzutreffen. Neben kleinen Schulen (in Hinsicht auf die Zahl der Lehrer und Schüler), deren Einzugsbereich kaum über den Ort und seine unmittelbare Umgebung hinausreichte, existierten Schulen mit weit überregionalem Ansehen und einem entsprechenden Andrang an Schülern. Man war sich dort der eigenen Bedeutung durchaus bewusst und konnte mit einiger Geringschätzung auf die „Trivialschulen", also auf die sozusagen normalen Gymnasien, blicken. So urteilt beispielsweise der Lehrer Heinrich Engelhard Poley am anspruchsvollen Weißenfelser „Gymnasium illustre“ recht wegwerfend über den Rektor der Ratsschule im gleichen Ort - den Hintergrund bildet ein Streit zwischen den beiden Lehrern: Er ist zwar ein kleiner Fuchs und Rector über einer gar zu kleinen Trivialschule: Allein er findet doch wobl mehr Beyfall, als Sie und ich; zumal da es hier noch ziemlich voll Unwisen ist [...]. ${ }^{9}$

Vor allem die seit $1635 \mathrm{zu}$ Sachsen gehörende Oberlausitz bildete mit ihren weithin berühmten Gymnasien (zu nennen sind hier zuerst und vor allem Görlitz,

7 Vgl. Katrin Keller, ,... das wir ieder zeith eine feine lateinische schul gehabt haben...“. Beobachtungen zu Schule und Bildung in sächsischen Kleinstädten des 17. und 18. Jahrhunderts, in: Holger Thomas Gräf (Hg.), Kleine Städte im neuzeitlichen Europa, Berlin 1997, S. 137-168. Nach Feststellung der Verfasserin war seit dem 16. Jahrhundert selbst in den kleinsten sächsischen Städten die Existenz einer Schule (mit wenigstens rudimentärem Lateinunterricht) selbstverständlich.

8 Vgl. Grosses vollständiges Universal-Lexicon aller Wissenschaften und Künste (Zedler), Bd. 57 (1748), Sp. 560 und 562.

9 Poley an Gottsched, 6. Dezember 1737. Vgl. Johann Christoph GotTsched, Briefwechsel. Historisch-kritische Ausgabe, Bd. 4 (1736-1737), hrsg. von Detlef Döring, Rüdiger Otto und Michael Schlott unter Mitwirkung von Franziska Menzel, Berlin/ New York 2010, S. 531-533. 
Zittau und Lauban) geradezu eine pädagogische Provinz. ${ }^{10}$ Das war nicht zuletzt das Verdienst einer Reihe von Rektoren, die als Pädagogen wie als Gelehrte im besten Rufe standen, weit über die Grenzen der Oberlausitz hinaus. Der berühmteste unter ihnen war ohne jeden Zweifel Christian Weise in Zittau, der in der Nachwelt bis heute noch am ehesten als Schriftsteller (Romane, Dramen, weniger die Lyrik) bekannt geblieben ist. ${ }^{11}$ In Görlitz waren es Christian Funcke und Samuel Grosser, die der Schule dreißig bzw. mehr als vierzig Jahre erfolgreich vorstanden. ${ }^{12}$ Unter den Laubaner Pädagogen ragte die Gestalt des Rektors Gottfried Hoffmanns hervor.

In den kursächsischen Kernlanden waren es über das gesamte Territorium verteilte Schulen, die in besonderem Ansehen standen. In Dresden ${ }^{13}$ existierte die altehrwürdige Kreuzschule; daneben erlebte die Annenschule in der ersten Hälfte des 18. Jahrhunderts eine Blütezeit, die allerdings der Siebenjährige Krieg, in dem die Preußen die Schule in Schutt und Asche legten, abrupt beendete. Wichtig war weiterhin die Zwickauer Ratsschule, die bereits im 16. Jahrhundert unter Stephan Roth $\mathrm{zu}$ höchstem Ansehen gelangen konnte, ${ }^{14}$ das im folgenden Jahrhundert Christian Daum aufrechtzuerhalten vermochte. ${ }^{15}$ In der Mitte des 18. Jahrhunderts wird die Schule von Christian Clodius geleitet, der lange Jahre als Student und Magister in Leipzig verbracht hatte und in dieser Zeit die dort schon 1697 gegründete „Görlitzsche poetische Gesellschaft“ grundlegend reformierte. Sein Nachfolger als Leiter der Gesellschaft, kein Geringerer als Johann Christoph Gottsched, hat in Anknüpfung an Clodius' Reformideen diese Sozietät unter dem Namen „Deutsche Gesellschaft“ zu nationalem Ruhm geführt. Zu nennen ist auch das Freiberger Gymnasium, das seit 1747 von Johann Gottlieb Biedermann, der

10 Vgl. Lars-Arne Dannenberg/Tino Fröde (Hg.), Bildung und Gelehrsamkeit in der frühneuzeitlichen Oberlausitz, Görlitz 2011.

11 Vgl. Hans Arno Horn, Christian Weise als Erneuerer des deutschen Gymnasiums im Zeitalter des Barock, Weinheim 1966.

12 Vgl. Ernst Kretzschmar, 400 Jahre höhere Schulbildung in Görlitz, Görlitz [1965]. Neuere Forschungsergebnisse zur Görlitzer Schulgeschichte bietet DANNENBERG/ FRÖDE, Bildung und Gelehrsamkeit (wie Anm. 10).

13 Zur Dresdner Schulgeschichte in dem uns hier interessierenden Zeitraum vgl. jetzt: Reiner Gross/Uwe John (Hg.), Geschichte der Stadt Dresden, Bd. 2: Vom Ende des Dreißigjährigen Krieges bis zur Reichsgründung, Dresden 2006, S. 278-281 und 727732.

14 Vgl. Regina Metzler (Hg.), Stephan Roth 1492-1546. Stadtschreiber in Zwickau und Bildungsbürger der Reformationszeit, Leipzig/Stuttgart 2008, zu Roth als Pädagogen S. 62-85. Die im Band edierten Briefe an Roth gehen oft auf Schulangelegenheiten ein.

15 Vgl. Richard Beck, Die Zwickauer Schule im Jahre 1676, in: Wissenschaftliche Beilage der Leipziger Zeitung, Jg. 1892, Nr. 31, S. 121-123 (gibt vor allem einen Überblick über die damalige Stundenplanung). Lutz Mahnke/Manfred Meltzer/Michael LöffLER, Christian Daum (1612-1687). Ein Zwickauer Rektor, Zwickau [1997], zum Schulleben im 17. Jahrhundert s. S. 19-22. InIs ZürNER, Herausragende Persönlichkeiten in der Geschichte der Ratsschulbibliothek Zwickau, in: 500 Jahre Ratsschulbibliothek Zwickau, Zwickau [1998], S. 38-66, zu Daum S. 51-59. 
bekanntlich eine Rolle in der Biografie Bachs spielte, geleitet wurde. ${ }^{16}$ Für uns wichtiger ist die Tatsache, dass er mit den „Acta Scholastica“ die erste pädagogische Fachzeitschrift Deutschlands überhaupt herausgab. ${ }^{17}$

Auch die 1657 eingerichteten drei Sekundogenituren in Merseburg, Weißenfels und Zeitz sind unter schulgeschichtlichen Aspekten nicht unbedeutend. Alle drei Herzogtümer strebten danach, ihre politische Schwäche durch besondere Leistungen auf den Gebieten der Kultur, der Kunst, aber auch der Bildung zu kompensieren. Das wohl ehrgeizigste Projekt bildete hier das 1664 in den Gebäuden eines aufgehobenen Frauenklosters gegründete Augusteum in Weißenfels. Es erreichte zeitweise fast das Niveau einer Universität, wie denn Rektor Christian Weidling im Jahre 1717 sich das Wagnis leistete, anlässlich des 200. Jahrestages des Beginns der Reformation Doktorpromotionen zu veranstalten. Das führte auf Anordnung des sächsischen Kurfürsten und polnischen Königs umgehend zu seiner Inhaftierung in der Leipziger Pleißenburg. Ein solches Agieren musste August der Starke als einen schweren Eingriff in die Rechte und Privilegien seiner beiden Landesuniversitäten betrachten. ${ }^{18}$

Das Zeitzer Gymnasium, um noch ein weiteres Beispiel zu nennen, besaß mit seinem Rektor Christoph Cellarius (1676 bis 1688 in diesem Amt tätig) einen der anerkanntesten Gelehrten der Zeit, der u. a. maßgeblich dazu beigetragen hat, die noch heute gültige Dreiteilung der Geschichte (Altertum, Mittelalter, Neuzeit) innerhalb der Historiografie durchzusetzen. Die Linien aller drei Sekundogenituren starben jedoch in der ersten Hälfte des 18. Jahrhunderts aus; die Territorien fielen an die Dresdner Hauptlinie der albertinischen Wettiner zurück. Das führte $\mathrm{zu}$ einem gravierenden Bedeutungsverlust der dortigen Gymnasien, die nun der unmittelbaren landesherrlichen Förderung entbehrten. 1787 jedenfalls urteilt der Rektor der Merseburger Schule: Hier fand ich eine Schule, deren Verfall alle

16 Vgl. Emil Preuss/Karl August Thümer, Quellenbuch zur Geschichte des Gymnasiums in Freiberg von der Zeit der Reformation bis 1842, Freiberg 1915, S. 197-200 (mit ausführlichem Verzeichnis der Schriften Biedermanns und Angaben zur weiteren Literatur über Biedermann). $\mathrm{Zu}$ Biedermann und Bach vgl. UlRich Leisinger, Biedermann und Bach - Vordergründe und Hintergründe eines gelehrten Streites im 18. Jahrhundert, in: Ulrich Leisinger/Christoph Wolff (Hg.), Musik, Kunst und Wissenschaft im Zeitalter J. S. Bachs, Hildesheim/Zürich/New York 2005, S. 141-167.

17 Der vollständige Titel lautet: Acta Scholastica, Worinnen Nebst einem gründlichen Auszuge derer auserlesensten Programmatum Der gegenwärtige Zustand Derer Berühmtesten Schulen und der dahin gehörigen Gelehrsamkeit entdecket wird, Leipzig/ Eisenach 1741 ff. Die Ziele dieser Zeitschrift formuliert Biedermann schon fünf Jahre zuvor in einem Brief an Gottsched: Behandelt werden sollen dort u. a.: Die auserlesensten materien, so jüngsthin in Schulreden abgehandelt worden. Die neuesten Bücher, so Schul-Männer herausgegeben. Die neuesten Bücher, so zum Schul-Wesen gebören. Die neuesten Veränderungen in Schulen. (Brief an Gottsched, 18. Mai 1736). Vgl. GotTsched, Briefwechsel, Bd. 4 ( wie Anm. 9), S. 102.

18 Zum Weißenfelser Augusteum liegt nun eine materialreiche Darstellung vor: Отто KLEIN, Gymnasium illustre Augusteum zu Weißenfels, 2 Bände, Weißenfels 2003/2007, zu den Promotionen von 1717 vgl. Bd. 2, S. 158-171. 
Beschreibung übersteigt; ein sogenanntes Gymnasium [...] in dessen Einrichtung und Administration fast keine Spur von gesunder Vernunft mebr zu seben war. ${ }^{19}$

In Leipzig schließlich sind es die Thomasschule als mittelalterliche und daher ältere Gründung und die zu Beginn des 16. Jahrhunderts ins Leben gerufene Nikolaischule, die in der Frühen Neuzeit als höhere Schulen galten. ${ }^{20}$ Im 18. Jahrhundert unterrichteten an beiden Schulen zeitweilig durchaus herausragende Gelehrte. Noch heute bekannt sind Johann August Ernesti (Thomasschule) und Johann Jakob Reiske (Nikolaischule). Trotz der Rolle, die Ernesti als einem der Wegbereiter des Neuhumanismus zukommt, lässt sich jedoch kaum behaupten, dass die Leipziger Schulen innerhalb der Entwicklung der Pädagogik im ausgehenden 18. Jahrhundert eine avantgardistische Funktion ausgeübt hätten. Einige spätere Beispiele werden das illustrieren.

Außer den eben aufgezählten Schulen existierte in den verschiedenen Gebieten Sachsens natürlich eine Reihe weiterer Einrichtungen, von denen diese oder jene zeitweise größere Bedeutung erlangen konnte. Das hing nicht allein, aber doch in der Hauptsache von den jeweiligen pädagogischen Qualitäten des Lehrpersonals ab. Überhaupt kommt diesem Faktor für die Prägung einer Schule eine große Rolle zu. Dazu treten spezifische Traditionen, wir werden z. B. noch vom Theaterspielen lesen, sodass bei allen gemeinsamen Grundsätzen doch nie einfach von ,den' Schulen in Sachsen gesprochen werden kann. Was deren Organisation angeht, so kann hier nur vermerkt werden, dass die Fürstenschulen der direkten Aufsicht der Landesregierung bzw. des Oberkonsistoriums in Dresden unterstanden, während das Patronat über die Lateinschulen Sache der jeweiligen Stadträte war. Diese legten auch die Lehrpläne fest, wobei man sich an die Kirchen- und Schulordnung von 1580, die fast zweihundert Jahre in Geltung blieb, zu halten hatte. ${ }^{21}$

19 Karl Traugott Thieme an Joachim Heinrich Campe, 25. Juni 1787. Zitiert nach: LudwiG FERTig (Hg.), Bildungsgang und Lebensplan. Briefe über Erziehung von 1750 bis 1900, Darmstadt 1991, S. 51-55, hier S. 52.

20 Maßgeblich ist nach einhundert Jahren immer noch: Oтто KaEmmel, Geschichte des Leipziger Schulwesens, Leipzig/Berlin 1909. Ein neuerer Sammelband fast Beiträge zu verschiedenen Aspekten der Schulgeschichte zusammen, darunter auch zu den Gelehrtenschulen: Detlef Döring/Jonas Flöter (Hg.), Schule in Leipzig. Aspekte einer achthundertjährigen Geschichte, Leipzig 2011. Im Rahmen seiner Ausführungen zum öffentlichen Schulwesen in Leipzig behandelt auch Thomas Töpfer beide Schulen: Töpfer, Die „Freyheit“ (wie Anm. 2), S. 150-166. Speziell zur Thomasschule vgl. jetzt Michael Maul, „Dero berühmbter Chor“. Die Leipziger Thomasschule und ihre Kantoren 1212-1804, Leipzig 2012. Folgende Publikation bringt zahlreiche neue Ergebnisse zur Erforschung der Geschichte des Thomanerchors, aber nur wenig zur eigentlichen Schulhistorie: Stefan Altner/Martin Petzoldt (Hg.), 800 Jahre Thomana. Glauben - Singen - Lernen. Festschrift zum Jubiläum von Thomaskirche, Thomanerchor und Thomasschule, Wettin-Löbejün 2012. Zur Nikolaischule ist zu verweisen auf: Frank Fehlberg/Florian Friedrich, 500 Jahre Nikolaitana. Beiträge und Dokumente zu einer Leipziger Schulgeschiche, Beucha/Markkleeberg 2012, S. 17-58 zur Geschichte bis ins 19. Jahrhundert.

21 Vgl. Ralph Thomas, Die Neuordnung der Schulen und der Universität Leipzig, in: Helmar Junghans (Hg.), Das Jahrhundert der Reformation in Sachsen. Festgabe zum 
Eine Vorstellung, die höheren Schulen in Sachsen seien von einem prozentual überwiegenden Teil der männlichen Jugend besucht worden, wäre irrig. Eltern, die ihren Söhnen und mitunter auch ihren Töchtern eine höhere Bildung angedeihen lassen wollten, konnten einen Hauslehrer, einen Informator, anstellen. Das kam außerordentlich häufig vor und war besonders in einer Universitätsstadt wie Leipzig relativ einfach zu bewerkstelligen, stand doch ein Überangebot von Studenten und Hochschulabsolventen als Kandidaten zur Verfügung. ${ }^{22}$ Es fehlte außerdem nicht an Vätern, die den Unterricht ihrer Kinder selbst übernahmen und diese entweder erst später oder gar nicht in eine öffentliche Schule schickten. Das absolute Gros der Jugend in den Städten allerdings frequentierte die sogenannten Winkelschulen, die immer privat betrieben wurden, aber oft einer gewissen Aufsicht seitens der Kommune unterworfen waren. ${ }^{23}$ Dort wurden als hinreichend betrachtete Grundkenntnisse im Lesen, Schreiben und Rechnen sowie in der Religionskunde vermittelt. Dieses Wissen konnte man allerdings auch in den unteren Klassen mancher Lateinschulen erwerben, deren Auftrag ja keineswegs darin bestand, alle ihre Schüler zur Hochschulreife zu führen. Auf dem flachen Land schließlich existierten die Dorfschulen, deren Anfänge bis in das Spätmittelalter zurückreichen. Diese bleiben jedoch außerhalb unseres Interesses.

Alle Überlegungen und Versuche, das eben skizzierte System entsprechend den sich wandelnden Bildungsanforderungen zu ändern bzw. zu erweitern, haben im 18. Jahrhundert lange Zeit kaum zu einem sichtbaren Erfolg geführt. Die Gymnasien öffneten sich nur bedingt, wir kommen noch darauf zu sprechen, solchen Fächern gegenüber wie Realienkunde und neueren Sprachen. ${ }^{24}$ Über Spezialschulen $\mathrm{zu}$ den immer wichtiger werdenden Bereichen Technik und Handel wurde nachgedacht, aber wenig in die Tat umgesetzt. Schon in den zwanziger Jahren schlug der wissenschaftlich gebildete Mechanikermeister Jakob Leupold in Leipzig die Gründung einer, wie wir heute sagen würden, Fachschule zur Handelsund Technikwissenschaft vor. ${ }^{25} \mathrm{Ob}$ allein nur sein vorzeitiger Tod den Plan zum

450jährigen Bestehen der Evangelisch-Lutherischen Landeskirche Sachsens, Berlin 1989, S. 113-131.

22 Vgl. Theresa Schmotz, Hauslehrer im Leipzig der Frühen Neuzeit, in: Döring/ FlÖTER, Schule in Leipzig (wie Anm. 20), S. 99-118.

23 Vgl. Thomas Töpfer, Schulwesen, Bildungsnachfrage und konkurrierende Unterrichtsangebote in Leipzig im 18. Jahrhundert, in: Stadtgeschichte. Mitteilungen des Leipziger Geschichtsvereins, Jg. 2008, S. 139-158.

24 Noch Ende des 18. Jahrhunderts gab es an der Nikolaischule in Leipzig keinen Unterricht in modernen Sprachen. Das berichtet jedenfalls Karl Burdach in seinen Erinnerungen: Auch neuere Sprachen wurden auf meiner Schule nicht gelebrt, und ich bekam im Französischen, Italienischen und Englischen Privatunterricht, da meine gute Mutter allen zu meiner Erziehung nöthigen Aufwand zu bestreiten wußte. Vgl. KARL FRIEDRICH BuRDACH, Rückblick auf mein Leben, Leipzig 1848, S. 38.

25 Vgl. Anton Weiz, Verbessertes Leipzig, oder die vornehmsten Dinge, so von Anno 1698 an biß hieher Bey der Stadt Leipzig verbessert worden, Leipzig 1728, S. 41. In den sechziger Jahren entstehen allerdings die Bergakademie in Freiberg und die Kunstakademie in Dresden bzw. Leipzig. 
Erliegen brachte, sei dahin gestellt. Erst gegen Ende des Jahrhunderts geraten die Dinge wieder in Bewegung, und das Schulwesen gewinnt einen differenzierteren Charakter, wie das Leipziger Beispiel der Gründung unterschiedlicher Schultypen zeigt. ${ }^{26}$ Die altsprachliche Ausbildung an den Gymnasien beanspruchte freilich noch bis ins 19., teilweise bis ins 20. Jahrhundert eine besondere Dignität. So klagt 1823 der zu dieser Zeit in Königsberg wirkende Philosoph und Pädagoge Johann Friedrich Herbart, dass die Bürgerschulen in der Öffentlichkeit im Vergleich zu den Gymnasien wenig geschätzt würden. Das sei das Ergebnis der Hingebung an unbestimmte Lobpreisungen der alten Sprachen, die an Charlatanerie grenzen. ${ }^{27}$

$\mathrm{Zu}$ den großen geistesgeschichtlichen Tendenzen des 18. Jahrhunderts zählen zuerst und vor allem Pietismus und Aufklärung. Wir werfen einen Blick auf deren Bedeutung im Schulwesen, speziell in Sachsen. Der Pietismus in seiner für Mitteldeutschland wichtigen und gerade für die Geschichte der Erziehung außerordentlich einflussreichen halleschen Prägung ${ }^{28}$ scheint in Sachsen im Rahmen der Pädagogik bzw. im Schulalltag keine größere Rolle gespielt zu haben. Das entspricht der relativ geringen Stärke der pietistischen Bewegung in Sachsen überhaupt. ${ }^{29}$ Dabei ist es nicht immer einfach, sozusagen gängige Äußerungen der Frömmigkeit der Zeit von pietistischen Ausformungen einer intensiven frommen Lebensführung zu unterscheiden. So mag Rektor Samuel Grosser in Görlitz mit seinem starken Insistieren auf einen frommen Lebenswandel pietistisch beeinflusst worden sein. Andererseits förderte er das den Pietisten verhasste Theater und bekämpfte alle Ansätze eines Konventikelwesens. ${ }^{30}$ Inwieweit in der Mitte des Jahrhunderts die Herrnhuter Einfluss an den Oberlausitzer Schulen gewannen, müsste noch untersucht werden. ${ }^{31}$ Immerhin war Gottfried Polycarp Müller, ein späterer Bischof der Herrnhuter Brüdergemeine, zuvor zeitweilig Rektor des Zittauer

26 Vgl. H. O. Zimmermann, Das Schulwesen der Stadt Leipzig, in: Schriften des Vereins für die Geschichte Leipzigs 1 (1872), S. 38-62, hier ein Überblick über alle Schulgründungen vom Ende des 18. Jahrhunderts bis zur Mitte des folgenden Jahrhunderts.

27 Johann Friedrich Herbart, Gutachten zur Abhülfe für die Mängel der Gymnasien und Bürgerschulen, in: ders., Pädagogische Schriften, hrsg. von Otto Willmann, 2. Bd., Leipzig 1880, S. 139-158, hier S. 153.

28 Vgl. Werner Loch, Pädagogik am Beispiel August Hermann Franckes, in: Hartmut Lehmann (Hg.), Geschichte des Pietismus, Bd. 4, Göttingen 2004, S. 264-308. Die Darstellung zur Pädagogik in diesem dem Einfluss des Pietismus auf die verschiedenen Lebensbereiche gewidmeten Band beschränkt sich ganz auf Francke und seine halleschen Anstalten.

29 Allerdings ist einschränkend zu bemerken, dass es zu diesem Thema an entsprechenden Forschungen fehlt. Unter dem sächsischen Adel scheint der Pietismus durchaus Einfluss besessen zu haben. Mehrere der adligen Träger des Rétablissements nach dem Ende des Siebenjährigen Krieges waren pietistisch geprägt.

30 Vgl. Detlef Döring, Die Geschichte der Deutschen Gesellschaft in Leipzig. Von der Gründung bis in die ersten Jahre des Seniorats Johann Christoph Gottscheds, Tübingen 2002, S. 35-37.

31 In Görlitz war der erklärte Herrnhuter Melchior Schäffer Beichtvater des Gymnasiums. Vgl. Döring, Deutsche Gesellschaft (wie Anm. 30), S. 128 f. 
Gymnasiums (und davor noch Professor an der Universität Leipzig). Als typischen Herrnhuter wird man Müller trotz seiner führenden Stellung innerhalb der Herrnhuter Gemeine gleichwohl nicht bezeichnen dürfen, denn seine Kritik an deren wissenschaftsfeindlichen Positionen führte zum heftigen Konflikt mit ihr. ${ }^{32}$

Spätestens seit den Forschungen von Horst Schlechte ist der Zusammenhang zwischen dem Rétablissement der Zeit nach 1763 und dem Pietismus hauptsächlich Hallenser Prägung bekannt. ${ }^{33}$ Zuerst und vor allem ist hier Peter von Hohenthal, Inhaber verschiedener hoher kursächsischer Ämter, zu nennen. ${ }^{34}$ Er entstammte der Leipziger Kaufmannsfamilie Hohmann, die 1717 von Kaiser Karl VI. als Edle von Hohenthal nobiliert worden ist. Zuerst stand Peter von Hohenthal dem Pietismus Hallescher Prägung nahe, später wandte er sich den Herrnhutern zu. Die Beschäftigung mit der Pädagogik begleitete ihn sein Leben lang. Ihren Ausdruck fand sie in einem entsprechenden publizistischen Schaffen und zugleich in praktischer Form. Hier ist zuerst die von ihm als Kreishauptmann des Kurkreises betriebene Gründung der Wittenberger Realschule (1756) zu nennen. Die Beeinflussung dieser Einrichtung durch die schulischen Anstalten in Halle ist mit Händen zu greifen, das zeigt allein schon die Tatsache, dass die ersten Lehrer aus Halle berufen worden sind. Auch weitere Schulgründungen gehen auf von Hohenthal zurück, sind aber im Bereich der Volks- und Armenschulen anzusiedeln.

Über die Präsenz aufklärerischer Ideen an den Schulen wissen wir nicht allzu viel mehr als über den Pietismus. Ein Thema bildete unbedingt das Vordringen der Philosophie von Leibniz und Wolff. Für einige Jahrzehnte ist sie die vorherrschende Schulphilosophie an den protestantischen Universitäten und Gymnasien (später auch an katholischen Einrichtungen). Die Vermittlung dieser Philosophie erfolgte weniger über die Lektüre der Originalschriften von Leibniz oder Wolff, sondern durch Lehrbücher, die den nicht immer einfachen Stoff schulgemäß und damit vereinfacht aufbereiteten. Weite Verbreitung über die Universitäten hinaus fand Gottscheds Kompendium „Erste Gründe der Weltweisheit“, aber auch die Lehrer selbst traten hier als Autoren in Erscheinung. Am erfolgreichsten wirkte auf diesem Gebiet der Görlitzer Rektor Friedrich Christian Baumeister. Seine Lehrbücher zur Philosophie Wolffs wurden weit über die Oberlausitz hinaus im Unterricht benutzt. Im Übrigen war Baumeister auch der erste Biograf des Schulhauptes. 35

32 Vgl. Отто Kaemmel, Gottfried Polycarpus Müller, in: Allgemeine Deutsche Biographie 22 (1885), S. 669-673.

33 Vgl. Horst Schlechte (Hg.), Die Staatsreform in Kursachsen 1762-1763, Berlin 1958, zum bildungsgeschichtlichen Hintergrund der am Reformwerk beteiligten Personen siehe S. 76-86.

$34 \mathrm{Zu}$ Hohenthal und seinem pädagogischen Wirken vgl. die ausführliche Darstellung bei Töpfer, Die „Freyheit“ (wie Anm. 2), S. 108-145.

35 Friedrich Christian Baumeister, Vita, fata et scripta Christiani Wolfii philosophi, Leipzig/Breslau 1739. 
Die Einführung der neuen Lehren an den kursächsischen Bildungseinrichtungen erfolgte keineswegs glatt und reibungslos. Vor allem der Widerstand der Theologen war erheblich. Durch das ganz und gar die Rolle der Vernunft betonende System der Leibniz-Wolffschen Philosophie sahen sie die christliche Religion in ihren Grundfesten bedroht. Das Eindringen dieses "Giftes“ in die Schulen galt es in ihren Augen zu verhindern. Aus Lübeck berichtete beispielsweise ein Lehrer über das Auftreten des dortigen, aus Leipzig stammenden Superintendenten Johann Gottlob Carpzov: ${ }^{36}$ Er sei ein hefftiger Feind der Wolfianer und wolle die Verbreitung der von ihnen vertretenen Lehren am Lübecker Gymnasium verhindern, ob er gleich durchgehends zeiget, daß er ibn [Wolff] nicht gelesen. ${ }^{37}$ Dass Carpzov aus Leipzig kommt, ist nicht von ungefähr. Die dortigen Theologen zählen zu den entschiedensten Gegnern der neuen Philosophie. Aber nicht nur Theologen, auch Philosophen, die dem Wolffianismus kritisch gegenüberstehen, versuchten dessen Umsichgreifen an den Schulen zu verhindern. Einer der eifrigsten war der bereits erwähnte Rektor Müller in Zittau, übrigens ein Schüler von Christian Thomasius. Johann Friedrich May, einer der entschiedensten Leipziger Wolffianer, berichtet von einem Besuch in der Oberlausitz: Der H. Director hat hier vielen den Geschmack an der Philosophie verderbt; und nicht wenigen, gar einen Ekel dawider beygebracht [...]. Nun, es lebe die wahre Philosophie. ${ }^{38}$ Welche Rezeption die Popularphilosophie und die ihr zeitlich folgende kritische Philosophie Kants oder auch die sich ab den siebziger Jahren entfaltende Literatur der deutschen Klassik an den Schulen fand, ist kaum bekannt. Vieles wird hier von den jeweiligen Lehrern abhängig gewesen sein. Nahmen sie selbst Anteil an den neuen Entwicklungen des Geisteslebens, so war zu erwarten, dass sie auch ihre Schüler in diese Beschäftigung einbezogen. So berichtet der im späteren Leben als Lexikonverfasser hervorgetretene Johann Gottfried Gruber davon, dass am Naumburger Gymnasium der junge Rektor Karl Gotthilf Jehnichen die Liebe zur Philosophie in ihm geweckt hätte, und so las er u. a. Schriften von Herder, Lessing, Engel und Zollikofer. ${ }^{39}$

36 Johann Gottlob Carpzov (1679-1767), 1713 außerordentlicher Professor der Theologie in Leipzig, 1730 Superintendent in Lübeck.

37 Lange an Gottsched, 4. Mai 1737, in: GotTsched, Briefwechsel, Bd. 4 (wie Anm. 9), S. 348-351, hier S. $350 \mathrm{f}$.

38 May an Gottsched, 31. Oktober 1734, in: Johann Christoph GotTsched, Briefwechsel. Historisch-kritische Ausgabe, Bd. 3 (1734-1735), hrsg. von Detlef Döring, Rüdiger Otto und Michael Schlott unter Mitwirkung von Franziska Menzel, Berlin/ New York 2009, S. 237-239, hier S. 238. May war in Leipzig, wo Müller an der Universität unterrichtet hatte, dessen Schüler gewesen.

39 Gruber an Böttiger, 20. Juli 1810. Vgl. Theodor Distel, Auszüge aus Briefen von Johann Gottfried Gruber an C. A. Böttiger, in: Berichte über die Verhandlungen der Königlich Sächsischen Gesellschaft der Wissenschaften zu Leipzig, Phil.-hist. Klasse 56 (1905), S. 271-292, hier S. 274. Jehnichen musste jedoch aus gesundheitlichen Gründen sein Amt bald niederlegen und starb kurze Zeit später. 
Eine Untersuchung über den etwaigen Einfluss des von Dessau aus wirkenden Philanthropinismus mit seiner Reformpädagogik auf Kursachsen gibt es nicht. Er scheint wohl eher gering oder nur partiell gewesen zu sein. Um das wirklich beurteilen zu können, wäre freilich eine weitaus bessere, auf den Quellen gegründete Kenntnis der einzelnen Schulgeschichten vonnöten. ${ }^{40}$ Wahrscheinlich könnte dann zumindest die Rezeption einzelner philanthropistischer Ansätze verfolgt werden. So ließe sich ein Einfluss des Philanthropismus bei dem Wirken des Roßlebener Konrektors bzw. dann Rektors Benedikt Wilhelm vermuten. Er steigt im Unterricht vom Katheder herunter und mischt sich unter seine Schüler. Der Lehrer und seine Schüler unternehmen gemeinsam Wanderungen durch die Natur und $\mathrm{zu}$ Orten von historischer Bedeutung. ${ }^{41}$ Das sind Unterrichtspraktiken, wie sie für den Philanthropismus typisch sind. Eine Sympathie für die Ideenwelt des Philanthropismus kann aber schon durch das äußere Erscheinungsbild eines Jugendlichen manifestiert werden, was damit den Unwillen der konservativen Lehrerschaft zu wecken vermag. So kleidet die Mutter des jungen Karl Burdach ihren Sohn gemäß der Vorstellungen der von ihr bewunderten pädagogischen Reformbewegung über die Pflege der Gesundheit. Das fand bei den Lehrern der Leipziger Nikolaischule jedoch gar keinen Anklang: so schadete mir doch dieses Basedowphilanthropinische Aussehen in den Augen des alten Rectors und ich konnte ibn durch die nun notbwendig gewordene Anlegung von Zopf und Halsbinde um so weniger aussöhnen, da sie einigermaßen illusorisch war [...].42 Auch der Sportunterricht, eines der zentralen Anliegen der vom Philanthropismus geprägten Pädagogik, stößt wohl nicht unbedingt auf Gegenliebe. In Schulpforte lehnt ihn der einflussreiche Rektor Carl David Ilgen jedenfalls ab. Allerdings stand hinter der Forderung der Einführung des Turnunterrichtes wohl eher das Drängen des ambitionierten Tanzlehrers Roller in Schulpforte. Für ihn stehen Turnen und Tan-

40 Vgl. Heikк Lempa, Bildung der Affekte. Der pädagogische Philanthropismus und die Entstehung des Bildungsbürgers, in: Erich Donnert (Hg.), Europa in der Frühen Neuzeit. Festschrift für Günter Mühlpfordt, Bd. 4, Weimar/Köln/Wien 1997, S. 215229. Die Wirkungen des Philanthropismus in Deutschland seien so gut wie unerforscht. Habe er vielleicht weniger als Gesamtphänomen gewirkt, so doch innerhalb „pädagogischer Randgebiete“. Ausdrücklich wird dann auf Gymnastik und Turnen verwiesen. Vgl. dazu auch die folgenden Ausführungen zu Schulpforte. Bereits vor 1800 habe man in Deutschland von den Bestrebungen der Philanthropen kaum Notiz genommen, meint Ulrich Herrmann, Die Pädagogik der Philanthropen, in: Klassiker der Pädagogik, 1. Bd., München 1991, S. 135-158, hier S. 156. Eine Wirkungsgeschichte des Philanthropismus sei nicht zu erkennen. Ob diese Behauptung in ihrer Schärfe zu halten ist, sei dahingestellt.

41 Vgl. Albrecht Graf von der Schulenburg, Die Klosterschule Rossleben, in: Gymnasien der Provinz Sachsen (wie Anm. 3), S. 55-82, hier S. 66 f. Roßleben gehörte bis $1815 \mathrm{zu}$ Kursachsen.

42 Vgl. Burdach, Rückblick (wie Anm. 24), S. 26. In einigen der Leipziger Schulgründungen um 1800 sollen Einflüsse des Philanthropinismus und (eher verhalten) Pestalozzis Raum gewonnen haben Vgl. Hans-Martin Modrow, Volksschule zwischen Staat und Kirche. Das Beispiel Sachsen im 18. und 19. Jahrhundert, Köln/Weimar/Wien 2007, S. $72-74$. 
zen in enger Verbindung. Das schließt eine Beeinflussung durch das relativ nahe gelegene Schnepfenthaler Philanthropinum, wo sportliche Übungen von großer Bedeutung waren, nicht aus. ${ }^{43}$ Das sind freilich alles nur sporadische Beobachtungen, die keine Verallgemeinerungen zulassen.

Wir wenden uns jetzt, hier liegt der Schwerpunkt des vorliegenden Beitrages, dem an den Schulen erteilten Unterricht zu. Eine ausführliche Darstellung würden schon die Lehrmethoden erfordern. Das kann an dieser Stelle nicht geschehen, nicht allein aus Raumgründen, sondern da es auch zu diesem Thema nur ganz ungenügende Vorarbeiten gibt. Eine spezielle Lehrerausbildung hat es bis ins 18. Jahrhundert nicht gegeben. Diese wurde eigentlich erst im 19. Jahrhundert mit den dann erfolgenden zahlreichen Gründungen von Lehrerseminaren zu einem Thema. Immerhin gab es zuvor entsprechende Ansätze der pädagogischen Ausbildung, vor allem in Halle und Göttingen. Für die mitteldeutschen Territorien war das Lehrerseminar in Kloster Bergen bei Magdeburg nicht ohne Bedeutung. Wer also an einer höheren Schule unterrichtete, der war ein Universitätsabsolvent, in sehr vielen Fällen ein Theologe. Zumindest das Amt des Rektors dürfte in der Regel von Theologen besetzt worden sein. ${ }^{44}$ Nicht untypisch ist die Biografie von Johann Heinrich Mücke, der in Wittenberg und Leipzig Theologie studierte und anschließend als Hauslehrer wirkte. 1766 wurde er ohne jede Erfahrung als Schullehrer zum Konrektor der Fürstenschule Grimma berufen. Es genügte dazu einfach eine Empfehlung seines Universitätslehrers Ernesti. ${ }^{45}$

43 Das geht aus einem Brief (10. Juni 1816) Wilhelm von Humboldts an Ilgen hervor. Vgl. Gerhard ARNHARDT, Schulpforte - eine Schule im Zeichen der humanistischen Bildungstradition, Berlin 1988, S. 256 (In Schulpforte werden zahlreiche Briefe Humboldts an Ilgen aufbewahrt, die in der genannten Publikation in Auswahl erstmals veröffentlicht wurden). Humboldt kritisiert Ilgens totale Ablehnung des „Turnwesens“. Von Berlin, Schulpforte war seit 1815 preußisch, war die Anordnung ergangen, Turnunterricht zu erteilen. Über die Anregung des Turnunterrichtes durch den Tanzlehrer Franz Anton Roller vgl. Karl Büchsenschütz/Petra Dorfmüller, Von Sachsen nach Preußen. Schulpforte in der ersten Hälfte des 19. Jahrhunderts, in: Flöter/Wartenberg, Die sächsischen Fürsten- und Landesschulen (wie Anm. 5), S. 116 f. Roller betrachtete den Turnunterricht als notwendige Voraussetzung für den Unterricht im Tanzen, der nach seiner Forderung in allen Gymnasien eingeführt werden sollte. Vgl. Franz Anton Roller, Systematisches Lehrbuch der bildenden Tanzkunst, Weimar 1843 (Reprint Leipzig 1989), S. V-X.

44 Noch 1751 wurde an der Fürstenschule in Meißen ausdrücklich festgestellt, dass nur ein Theologe Rektor werden könne, da dieser an den Bußtagen vor der gesamten Schule eine Buß-Vermabnung abzuhalten habe, wozu eben nur ein Theologe in der Lage sei. Vgl. Sächsisches Staatsarchiv - Hauptstaatsarchiv Dresden (im Folgenden: HStA Dresden), Loc. 1815, Acta derer vacanten Praeceptorum Stellen bey der LandSchule Meißen betr., Bl. 61-65.

45 Vgl. Eberhard Zänker, Über Seumes Grimmaer Freund Johann Heinrich Mücke, in: Jörg Drews (Hg.), In Polen, Palermo und St. Petersburg. Vorträge der Colloquien zu Johann Gottfried Seume in Grimma, Riga und Tartu 2003 und 2005, Bielefeld 2008, S. 135-145. 1782 wurde Mücke Rektor der Schule. Die Auffassung, die pädagogischen Fähigkeiten würden sich sozusagen von selbst einstellen, wenn man als Lehrer tätig geworden ist, muss verbreitet gewesen sein. Als sich der Arabist Reiske um die Stelle 
Schon die im Vergleich zu anderen Positionen geringfügige Entlohnung, die man als Lehrer zu erwarten hatte, ließ vielen diese Beschäftigung eher als Übergangslösung erscheinen, die möglichst rasch mit einer lukrativeren Anstellung, vor allem im Pfarramt, vertauscht werden sollte. ${ }^{46}$ Erfolg erzielte bei dieser schwierigen Suche aber wohl eher eine Minderheit, und für den größeren Teil der Universitätsabsolventen bedeutete das Lehrerdasein ein Lebensschicksal. Was die Unterrichtsmethoden betrifft, so näherten sich diese an den ambitionierten Schulen dem Vorbild der Universitäten. Schließlich sollten diese Schulen ihre Zöglinge auf den Besuch der Universität vorbereiten, auch wenn bei weitem nicht alle ihre Absolventen diesen Weg beschritten. Manche Pädagogen, die ja durch die Bank weg an den Philosophischen Fakultäten, dann oft außerdem an den Theologischen studiert hatten, versuchten schon an der Schule universitären Lehrbetrieb in Miniaturform zu gestalten. Dazu zählte die Disputation, neben der Vorlesung die gängigste Lehrform an den Universitäten. In der obersten Klasse, also in der Prima, war es nicht selten, dass die Lehrer, meistens war es der Rektor, solche Übungen anboten. Der spätere Radikalaufklärer Johann Christian Edelmann berichtet in seinen Erinnerungen über seine Erlebnisse am Laubaner Gymnasium: Unter den Schulübungen gefiel mir keine besser als das Disputiren [...]. Es stand uns frey, die Sätze, worüber wir disputiren wollten, selber zu erwäblen, und der Rector war allemabl Präses [...], wir dispuirten das blane vom Himmel, und das schwarze von der Erde, und wenn wir ausdisputirt hatten, war einer so klug, als der andere [...]. ${ }^{47}$

Eine andere da und dort zu verfolgende Tendenz der Zeit bildete der Versuch, ältere Schüler zur Aufsicht und zur Unterrichtung der Jüngeren heranzuziehen. In Meißen wird 1727 der Versuch unternommen, sogenannte Collaboratores einzuführen, die ihre Mitschüler überwachen und bei Abwesenheit der Lehrer den Unterricht übernehmen sollen. Ausdrücklich wird festgehalten, dass die Collaboratores Schüler sein sollten, die sich dermaleinst dem Lehrerberuf widmen

des Rektors der Leipziger Nikolaischule bewarb, begegnete er dem Argument, er verfüge über keine Erfahrungen als Lehrer, mit der Bemerkung: Es liegen zuweilen Geschicklichkeiten in dem Menschen verborgen, welche sich allererst entwickeln, wenn Veranlaßungen sich rege machen. Werde er erst einmal in die Situation versetzt, Unterricht erteilen zu müssen, so werde er diese Fertigkeit schon entwickeln. Vgl. Richard Förster (Hg.), Johann Jacob Reiskes Briefe, Leipzig 1897, S. 586 (Brief an Jacob Heinrich Born, 28. März 1758).

46 Dass die gemeinhin kläglichen Einkünfte, die man als Lehrer zu erwarten hatte, den pädagogischen Elan nicht gerade förderten, beklagt der Biograf Gellerts: Die gemeiniglich geringen Einkünfte ihrer Lehrer, überhoben sie kaum der ängstlichen Sorgen für ibren Unterhalt [...]. Ihr Unterricht kann also nicht sebr vollkommen seyn [...]. Vgl. Johann Andreas Cramer, Christian Fürchtegott Gellerts Leben, in: Christian Fürchtegott Gellert, Sämmtliche Schriften, 10. Theil, Leipzig 1839, S. 175-311, hier S. 181. Die Biografie erschien erstmals 1774.

47 Johann Christian Edelmann, Selbstbiographie, hrsg. von Carl Rudolph Klose, Berlin 1849 (Nachdruck Stuttgart-Bad Cannstatt 1976), S. 15. 
wollten. Das System scheint jedoch nicht recht funktioniert zu haben. ${ }^{48}$ Am Torgauer Gymnasium wiederum war es zu Beginn des 19. Jahrhunderts üblich, dass Primaner unter Aufsicht der Lehrer jüngere Schüler (Haufen Unterer) unterrichteten. ${ }^{49}$

Die Beherrschung der alten Sprachen bildete, wie schon eingangs vermerkt, das Hauptziel des Unterrichts. Dabei spielte das Griechische entgegen der ursprünglichen Intention der Humanisten eine nur untergeordnete Rolle. An den Fürstenschulen allerdings wurde in dieser Hinsicht wohl immer ein gewisses Niveau aufrechterhalten. Deutlich weniger intensiv wurde die griechische Sprache an den Lateinschulen betrieben; über die Lektüre der Koine des Neuen Testaments kam man nur selten hinaus. Erst die neuhumanistische Bewegung des 18. Jahrhunderts leitete hier einen allmählichen Wandel ein.

Latein aber musste bzw. sollte nicht nur in der Schrift, sondern auch mündlich vollständig beherrscht werden. Dementsprechend nimmt der Lateinunterricht eine dominierende Position innerhalb der Lehrpläne ein. In Zwickau werden je nach Klassenstufe 14 bis 17 Stunden wöchentlich Latein gelehrt; 50 das dürfte dem Durchschnitt an den sächsischen Schulen entsprochen haben. Wenigstens an den Fürstenschulen war es den Eleven generell verboten, die Muttersprache zu verwenden; das galt auch für das ganz privat geführte Gespräch. Am Laubaner Gymnasium übte der Rektor die Primaner darinnen, daß sie alles, was sie redeten und schrieben, Lateinisch abfassen musten. ${ }^{51}$ Eine selbstverständliche Unterrichtssprache war das Latein an manchen Schulen noch im frühen 19. Jahrhundert, als dies an den Universitäten bereits fast ganz außer Gebrauch gekommen war. Das belegen u. a. die Erinnerungen des späteren Philologieprofessors Hermann Koechly an seine Zeit in Grimma: die griechischen und lateinischen Autoren wurden nur lateinisch interpretirt [...] und lateinische Disputationen über allgemeine Themata

48 Vgl. Detlef Döring, Die Fürstenschule in Meißen zur Zeit des jungen Lessing, in: Flöter/Wartenberg, Die sächsischen Fürsten- und Landesschulen (wie Anm. 5), S. 91 f. In Schulpforte wird das Amt des Collaborators 1800 eingeführt, aufgrund des Scheiterns der damit verbundenen Intentionen aber wieder abgeschafft. Vgl. BüCHSENschüTz/ DORFMÜller (wie Anm. 43), S. 114.

49 Vgl. Annemarie Müller, Aus den Lebenserinnerungen von Gustav Deutschmann (1807-1886), in: Kleine Schriften des Torgauer Geschichtsvereins 11 (1999), S. 29-49, hier S. 44. In Schulpforte versammelte ein Schüler einer höheren Klasse jüngere Schüler um sich und unterrichtete sie: Saben sich die jüngeren Schüler bierdurch auf das Beste gefördert, so war es auch für ibre jugendliche Lebrer vom größten Werth [...] weil sie die Gabe der Mittheilung, die Gabe des klaren, geordneten Sprechens übten [...]. Vgl. Friedrich HeINRICH RANKe, Jugenderinnerungen mit Blicken auf das spätere Leben, Stuttgart 1877, S. $33 \mathrm{f}$.

50 Vgl. Beck, Die Zwickauer Schule (wie Anm. 15), S. 122. Mathematik wurde zwei Stunden unterrichtet. Dem Griechischen wurden 2 bis 5 Stunden gewidmet. Das Pochen auf die Notwendigkeit des Lateinunterrichtes war im Übrigen wohl nicht allein ein Anliegen der Lehrerschaft. Die Bürgerschaft selbst kleiner Orte hielt die Vermittlung von Lateinkenntnissen für unabdingbar. Vgl. Keller, Beobachtungen (wie Anm. 7), S. 150.

51 Vgl. Zedler (wie Anm. 8), Sp. 562. 
bistorischen oder philosophischen Inhalts in der Prima brachten noch zu meiner Zeit die schriftliche und mündliche Handhabung des Lateinischen zu einer Sicherheit und Gewandtheit, von welcher man heut zu Tage keinen Begriff mehr hat. ${ }^{52}$

Das Ziel, eine optimale Sicherheit im aktiven Gebrauch der lateinischen Sprache zu erlangen, hatte verschiedene Folgen. Worauf es ankam, das war das Einpauken, das Auswendiglernen der Grammatik, gleichgültig ob man mit dem so eingebläuten Wissensstoff im späteren Leben tatsächlich etwas anfangen konnte..$^{53} \mathrm{Die}$ Beschäftigung mit den Texten der antiken Literatur besaß dagegen eher nachgeordnete Bedeutung. Man las auch immer seltener die für das Unterrichtsziel weniger brauchbaren Texte der Antike, sondern zog stattdessen moderne, d. $h$. neulateinische Schriften vor. Eine Schule, in der man diesen Kurs besonders streng verfolgte, war die Leipziger Thomasschule um $1700 .{ }^{54}$ Mit besonderem Eifer aber wurden stilistische und grammatische Übungen betrieben. Bezeichnenderweise wurde ein Kandidat für das Amt des Konrektors an der Meißner Fürstenschule allein daraufhin geprüft, wie er die klassischen Autoren grammatikalisch, rhetorisch und philologisch interpretieren kann; von Erläuterungen zu Inhalten der

52 Vgl. Hermann Koechly, Gottfried Hermann. $\mathrm{Zu}$ seinem hundertjährigem Geburtstage, Heidelberg 1874, S. 109. Koechly berichtet hier aus seiner eigenen Schulzeit in den Jahren 1827 bis 1832. Ungefähr zur gleichen Zeit besuchte Gustav Deutschmann in Torgau das Gymnasium. Am Ende der Schulzeit konnte er Lateinisch ziemlich geläufig sprechen und sich auch im Griechischen ziemlich fertig ausdrücken. Vgl. MüLlER, Lebenserinnerungen (wie Anm. 49), S. 44.

53 Manche Schüler konnten dieser Methode durchaus etwas abgewinnen, z. B. der später in England wirkende Geistliche Johann Gottlieb Burckhardt, der das Gymnasium in Eisleben besuchte: Ich habe, so wie in der Religion, also auch in den Wissenschaften, in meiner Jugend vieles auswendig gelernt, obne es zu verstehen. Dadurch habe ich den Vorteil gehabt, daß mein Gedächtnis geübt worden ist, und der Verstand, da er aufwachte, gleichsam Materialien vorfand, über welche er nachdenken konnte." Vgl. Johann Gottlieb Burckhardts Lebensbeschreibung von seiner Geburt 29. Februar 1756 zu Eisleben bis zu seiner Trauung am 3. September 1786 zu Wolkwitz. Der Text ist als eine im Besitz der Familie Burckhardt befindliche Handschrift überliefert und wurde in einer Transkription von einem Nachkommen, Pfarrer Klaus J. Burckhardt, im Internet veröffentlicht. Herr Burckhardt hat mir in einem Schreiben vom 4. Mai 2002 gestattet, aus diesem Text zu zitieren. Die Internet-Adresse (http://bs.cyty.com/elmbs/jb.htm) ist heute allerdings nicht mehr auffindbar. Ich zitiere hier und an einer anderen Stelle nach dem Ausdruck, den ich von dem gesamten Text am 4. April 2002 angefertigt habe. Andere Schüler behielten diesen Unterricht lebenslang ausgesprochen negativ in Erinnerung: Wir lagen in den Vorhallen der Philologie wie die Kranken um den Teich Bethseda und warteten auch, daß ein Engel herabkäme und die Wasser bewegte, damit aus ibnen der Hauch des alten Heils aufstiege und uns kräftige. So quälte denn auch ich mich durch die Alten hindurch [...] aber keine Freude ging mir dabei auf! (CARL Gustav Carus, Lebenserinnerungen und Denkwürdigkeiten, 1. Bd., Weimar 1966, S. 38 f.). Carus besuchte die Leipziger Thomasschule.

54 Vgl. Encyklopädie des gesammten Erziehungs- und Unterrichtswesen, 4. Bd., Leipzig 1881, S. 264. Der hier benutzte Lexikonartikel (Lateinischer Unterricht) enthält zahlreiche Mitteilungen, die den oben mitgeteilten Charakter des Lateinunterrichts belegen. 
Texte ist nicht die Rede. ${ }^{55}$ Übersetzungen aus dem Lateinischen ins Deutsche oder umgekehrt waren in der Schulpraxis tägliches Geschäft. Bei den Übersetzungen aus dem Deutschen wurden die Texte so formuliert, dass die einzupaukenden grammatischen Regeln des Lateinischen daran zu üben waren. Das mag, wenn wir Karl Philipp Moritz' „Anton Reiser“ folgen, unbeabsichtigt auch der besseren Erfassung der deutschen Muttersprache gedient haben. ${ }^{56}$ Unabdingbar waren Fähigkeiten und Fertigkeiten im Abfassen lateinischer Gedichte, die oft bestimmte Anlässe zum Hintergrund hatten, u. a. Schulfeierlichkeiten. Sowohl in der Prosa wie in der Poesie war der Gebrauch eines seltenen Vokabulars und schwieriger Satzkonstruktionen beliebt. ${ }^{57}$ Begehrt waren daher Florilegien, die entsprechendes Wort- und Satzmaterial aus der überlieferten Literatur herauszogen, z. B. Caspar von Barths „Adversaria“, die bevorzugt nichtklassische, oft archaisch anmutende Texte erfassten. ${ }^{58}$ Großer Wertschätzung erfreute sich schließlich die

55 HStA Dresden, Loc. 1815, Acta derer vacanten Praeceptorum Stellen bey der Landschule Meißen betr., Bl. 35-36 (datiert auf den 16. Januar 1736). Schon Ende des 17. Jahrhunderts beklagte Samuel Pufendorf, dass die Schüler mit Grammaticken, Logicken, Rhetoricken und dergleichen Bärenbäuterey geplagt würden. Sie würden so nichts lernen. Er, Pufendorf, habe in der Schule (Grimmaer Fürstenschule) denselben Quarck fabren lassen, um sogleich Autores Graecos et Latinos zu lesen (Pufendorf an seinen Bruder Jeremias, 26. Juli 1690. Vgl. Samuel Pufendorf, Briefwechsel, hrsg. von Detlef Döring, Berlin 1996, S. 280). Einhundert Jahre später herrschen an vielen Schulen immer noch die gleichen Verhältnisse. Ein Beispiel bildet das Gymnasium zum Grauen Kloster in Berlin. Nie gelangten wir, erinnert sich ein früherer Schüler, zu einem Ueberblick der Gedanken des Autoris, und erst späterbin empfand ich das Vergnügen des Lecture der Classicer durch das Beachten nicht ibrer Worte sondern ibrer Gedanken. Vgl. Peter Hermann, Leben und Werk des brandenburgischen Superintendenten Wilhelm Gabriel Wegener (1767-1837) im Spiegel seiner Autobiographie, in: Erich Donnert (Hg.), Europa in der Frühen Neuzeit. Festschrift für Günter Mühlpfordt, Bd. 7, Köln/Weimar/Wien 2008, S. 399-533, hier S. 440. Wegener besuchte die Schule von 1782 bis 1785 .

56 Hier benutzt nach folgender Ausgabe: Karl Philipp Moritz, Werke, Bd. 1., hrsg. von Heide Hollmer/Albert Meier, Frankfurt a. M. 1999, S. 212 f. Ein seltenes überliefertes Beispiel für solche Übersetzungsübungen bieten die an der Leipziger Thomasschule verfassten Schulhefte von Wilhelm Friedemann Bach (heute im Bach-Museum Eisenach), dem ältesten Sohn des großen Musikers. Die dort niedergeschriebenen deutschen Texte wurden diktiert. Der Schüler musste sie dann ins Lateinische oder Griechische übertragen. Mit dem Griechischen hatte Friedemann Bach offenkundig große Schwierigkeiten; Latein lag ihm näher. Vgl. Conrad FreYse, Die Schulhefte Wilhelm Friedemann Bachs, in: Bach-Jahrbuch 39 (1951/52), S. 103-119.

57 Diese "Vergewaltigung" des Lateins in den Schulen stieß zunehmend auf die zeitgenössische Kritik, z. B.: Man mag auch hier diejenigen neugebackenen Lateinischen Poeten nicht vergessen, welche, um nur den Vers voll zu machen, das Latein zusammen raspeln, wie es ibnen vorkommt. Sonderlich thun einen guten Lateiner die Obren weh, wenn er die gezwungenen Anagrammata, Chronosticha, Acrosticha, Palindroma, cabbalistica lieset, worinnen die licentia poëtica gemeiniglich die Reinigkeit der Sprache unterdrücket. Vgl. Acta scholastica, 3. Stück, Leipzig/Eisenach 1741, S. 191. Die Verbesserung der Methoden des Lateinunterrichts zählt zu den häufigen Themen dieser Zeitschrift.

58 Vgl. Johannes Hoffmeister, Kaspar von Barths Leben, Werke und sein Deutscher Phönix, Heidelberg 1931, S. 27. Barth verbrachte die letzten Jahrzehnte seines Lebens in Leipzig. 
Rhetorik. Das Abfassen und Vortragen lateinischer, im wachsenden Maße aber auch deutscher Reden zählte zu den gebräuchlichen Übungen. ${ }^{59}$ Das alles sind freilich nur einige generalisierende Feststellungen. In der jeweils konkreten Schulwirklichkeit werden sich die Verhältnisse differenziert dargeboten haben. Nicht zuletzt kam es auf das Wirken des einzelnen Lehrers an.

$\mathrm{Ab}$ Mitte des 18. Jahrhunderts ändern sich, wenn auch nur allmählich, Methoden und Intentionen des Unterrichts. An die Stelle des monotonen Einpaukens von Grammatik und Wortschatz sowie der rein formalen Nachahmung der Sprache der „Alten“ tritt eine stärkere Beschäftigung mit den antiken Texten und ihren Inhalten und zwar im Blick auf den praktischen Nutzen der Lektüre jenseits der reinen Philologie. Die Antike bleibt Vorbild, aber nicht mehr im Sinne der reinen äußeren Nachahmung von Sprache und Stil, sondern als Anleitung zur allseitigen Persönlichkeitsbildung. Das ist das Programm des Neuhumanismus, an dessen frühen Ausbildung zwei Leipziger Lehrer einen maßgeblichen Anteil nahmen, Johann Matthias Gesner und Johann August Ernesti, beide tätig als Rektoren der Thomasschule. Ernesti ist dann auch derjenige, der die pädagogikgeschichtlich nicht unbedeutende kursächsische Schulordnung von 1773, die endlich die Ordnung von 1580 ablöste, im neuhumanistischen Sinne entscheidend geprägt hat. Eine andere, bekanntlich bei allen je proklamierten Verordnungen zu stellende Frage ist die, inwieweit sich jene Reformideen in der Praxis durchzusetzen vermochten. Die Antwort geht, wenigstens für längere Zeit, eher in eine negative Richtung. An den Schulen blieb, nach allem was wir wissen, der rein philologisch orientierte Betrieb wohl auf geraume Zeit noch von beherrschender Bedeutung. Dem Reformer Ernesti selbst wurde von einem seiner Schüler, es war der berühmte Dichter Jean Paul, vorgeworfen zwar gute lateinische Worte setzen zu können, aber zu keinem herlichen Gedanken in der Lage zu sein. 60 Ähnliches wird über den Rektor der Nikolaischule, Georg Heinrich Martini, berichtet. Sein viel-

59 Eine Unmenge handschriftlich überlieferter Schulreden des frühen 18. Jahrhunderts hat sich in vier Sammelbänden der Universitätsbibliothek Leipzig erhalten (Ms 0408). Sie sind am Stettiner Gymnasium gehalten worden, entsprechen in Themenwahl und Anlage aber wohl auch den Redeübungen sächsischer Gymnasien. Den absoluten Schwerpunkt bilden Reden zu religiösen Themen (z. B. Oratio de captivitate Jesu, Oratio de vero hujus mundi salvatore, Oratio de sepultra Christi). Es finden sich aber auch Reden über die Nützlichkeit der Lotterien, die „Lustbarkeit des Frühlings“ oder über das „Lob der Keuschheit“. Vgl. Detlef Döring, Katalog der Handschriften der Universitäts-Bibliothek Leipzig, Neue Folge, Bd. I, Teil 2: Die neuzeitlichen Hand. schriften der Nullgruppe (Ms 0301-0600), Wiesbaden 2002, S. 135-145. An der Meißner Fürstenschule werden wenige Jahrzehnte später auch Reden gehalten, die sich mehr oder minder auf gegenwärtige politische Entwicklungen beziehen, z. B.: De Austria per feminas amplificata, De Saxonum Principibus Imperii orbi tutoribus. Vgl. HStA Dresden, Loc. 1802: Protocoll und Verzeichnüß deßen, was vom Anfang meines ge. führten Rectorats vom 7 Novembr. 1735 [...] anzumerken [...] verfaßt von M. Theophilo Grabnern, S. 149 (Protokoll vom 14. Dezember 1741).

60 Jean Paul an Erhard Friedrich Vogel, November 1781 (Brief nicht abgesendet). Zitiert nach: Jean Paul, Hungerjahre in Leipzig. Briefe aus der Studentenzeit 1781-1784, Leipzig 2003, S. 27-37, hier S. 31. 
leicht bekanntester Schüler, Johann Gottfried Seume, urteilt über den Unterricht des Rektors: [...] er richtete sich so sehr nach der Form, daß fast das Wesen darüber verlorenging. Hier wurde denn auch gedichtert oder vielmehr nur geverselt. Martini habe, wird präzisiert, Gedichte in Prosatexte umgewandelt und den Schülern die reichlich monotone Aufgabe gestellt, die Verse wieder zu rekonstruieren. ${ }^{61}$ Das sind reine Geschicklichkeitsübungen, die mit einer inhaltlichen Aneignung der Texte wenig zu tun haben. Die anderen Lehrer an der Nikolaischule waren nicht besser, will man einer anderen Schülererinnerung glauben: Der Tertius $M$. Lunz, las mit den beiden Oberklassen, so lange ich die Schule besuchte, nur ein paar Komödien des Terenz, wußte aber auf keine Weise die Schüler in das Interesse der Stücke einzufübren, oder sonst ibre Phantasie zu erregen. ${ }^{2}$ Auch in Schulpforte lag der Schwerpunkt des Unterrichts bei solchen uns seltsam anmutenden formalen Übungen. Rektor Carl David Ilgen pflegte, wie sich sein ehemaliger Schüler Leopold Ranke erinnert, als vornebmste Action Texte zu diktieren, die dann in lateinische Verse umzusetzen waren. ${ }^{63}$ So spricht denn wohl ein Schüler Ilgens aus dessen Zeit als Rektor des Naumburger Ratsgymnasiums für viele Abgänger der sächsischen Lehranstalten insgesamt, wenn er als abschließende Erkenntnis seiner Schulausbildung resümierend mitteilt: Der Philolog schien mir der seligste Mensch auf Erden. ${ }^{64}$ Eine intensivere Umsetzung des neuhumanistischen Bildungsprogrammes erfolgte erst im 19. Jahrhundert und auch dann wohl nur partiell.

Wenigstens hingewiesen sei darauf, dass der Sprachunterricht auch Gelegenheit bot, Kenntnisse zu Fächern zu vermitteln, die im offiziellen Curriculum der

61 Johann Gottrried Seume, Mein Leben. Zitiert nach: Seumes Werke in zwei Bänden, hrsg. von Anneliese und Karl-Heinz Klingenberg, 1. Bd., Weimar 1962, S. 67. Bemerkenswert ist Seumes Hinweis, Martini habe eine große Sammlung von Büchern zu den Altertümern besessen, die er aber nicht an seine Schüler vermittelte (S. 66 f.). An der Thomasschule sah es nach den Erinnerungen von Friedrich Rochlitz ähnlich aus. Der dortige Rektor Johann Friedrich Fischer, ein weitbekannter Philologe, erläuterte die Texte allein der Sprache nach, diese aber blos grammatisch und kritisch; letztes jedoch nur zur Prüfung der Lesarten. Über den Inhalt der behandelten antiken Texte sei niemals gesprochen worden. Zitiert nach: Bernhard Knick (Hg.), St. Thomas zu Leipzig. Schule und Chor, Wiesbaden 1963, S. 241.

62 Universitätsbibliothek Leipzig, Rep. VI 25q: Memoiren von Christian Weiss (Regierungs- und Schulrat in Merseburg). Es handelt sich bei der benutzten Handschrift um eine Abschrift, die eine Tochter von Weiss vom Original anfertigte.

63 Vgl. Leopold von Ranke, Zur eigenen Lebensgeschichte, hrsg. von Alfred Dove, Leipzig 1890, S. 19. Gleiches berichtet sein Bruder Friedrich Heinrich. Ilgens Prosatexte hätten meistens Themen der älteren vaterländischen Geschichte behandelt. Besonders eifrige Schüler hätten den Text noch zusätzlich in griechische Verse umgesetzt. Eine andere Übung Ilgens bestand darin, Briefe zeitgenössischer Gelehrter ins Lateinische übersetzen zu lassen. Namentlich werden Schreiben des Leipziger Nikolaischulrektors Johann Jakob Reiske erwähnt, der freilich ein eher ungewöhnliches Deutsch schrieb. Vgl. Ranke, Jugenderinnerungen (wie Anm. 49), S. 37 f. und 46. Vgl. zum Sprachunterricht in Schulpforte Heumann, Schulpforta (wie Anm. 5), S. 90-97. 
Schulausbildung noch nicht vertreten waren. Das gilt insbesondere für Geschichte und Geografie. Beide Disziplinen hatten selbst an den Universitäten noch um ihre Selbstständigkeit zu ringen, waren aber unter Studenten und Schülern gefragt, denn zum Wissen eines „homo politicus“, der sich in den Dienst eines Gemeinwesens zu stellen vermochte, zählten historische und geografische Kenntnisse unbedingt. ${ }^{65}$ Im Rahmen des Unterrichts in den antiken Sprachen wurden natürlich auch Schriften von Historikern berücksichtigt. Soweit man über die formale Behandlung dieser Texte überhaupt hinausging und sich mit ihren Inhalten beschäftigte, war es aber allein die Geschichte des Altertums, die Berücksichtigung fand. Allerdings ist hier, wie auch bei anderen Fächern (z. B. bei der noch zu erwähnenden Mathematik), immer davon auszugehen, dass die Lehrer außerhalb der regulären Unterrichtszeit zusätzliche Lehrstoffe vermittelten, die dort nicht vertreten waren. Auch war an manchen Schulen, insbesondere den Fürstenschulen, für die Schüler die Möglichkeit gegeben, in der durchaus zugelassenen Privatlektüre sich manches für notwendig gehaltene Wissen eigenständig anzueignen.66 Kenntnisse zur neueren und neusten Geschichte können also auf diesem Wege zum geistigen Rüstzeug der abgehenden Schüler geworden sein.

Was den zweiten Schwerpunkt der Schulbildung betrifft, die religiöse Erziehung, so lässt sich noch schwerer etwas über die Ergebnisse dieser Bemühungen sagen. In den Stundenplänen wurde der Religionsunterricht, über lange Zeit hinweg meist in Anlehnung an Leonhard Hutters verbreiteten „Loci“, mit vielen Stunden berücksichtigt. In Zwickau z. B. sind es je nach Klassenstufe vier bis zwölf Stunden in der Woche. ${ }^{67}$ Das Gebet bildete in den Schulen eine allgegenwärtige Übung. Der Besuch der in ihrer zeitlichen Ausdehnung heute Erstaunen erregenden Gottesdienste an Sonn- und Feiertagen galt als selbstverständlich. ${ }^{68}$

65 Vgl. Detlef Döring, Inhalt und Funktion des Geschichtsunterrichts bei Christian Weise, in: Roswitha Jacobsen (Hg.), Weißenfels als Ort literarischer und künstlerischer Kultur im Barockzeitalter, Amsterdam 1994, S. 261-293.

66 Dass Samuel Pufendorf während seiner Zeit an der Grimmaer Fürstenschule so viele antike Autoren lesen konnte, wurde durch die dort täglich gewährten Freistunden gefördert (vgl. Anm. 55). In Schulpforte waren 150 Jahre später die Verhältnisse ähnlich geregelt. Friedrich Heinrich Ranke z. B. lernt in den Freistunden Italienisch. Es hätte überhaupt viele Zeit zu freier Arbeit gegeben. Vgl. Ranke, Jugenderinnerungen (wie Anm. 49), S. 33 und 47.

67 Beck, Die Zwickauer Schule (wie Anm. 15), S. 122. Zwölf Stunden wird in der untersten Klasse, der Septima, unterrichtet. In Schulpforte wurde zu Beginn des 19. Jahrhunderts in allen Klassen zweimal in der Woche Religionsunterricht erteilt, der zugleich in den Dienst des Sprachunterrichtes gestellt wurde. Die Schüler mussten die biblischen Texte in deren Grundsprachen lesen und ins Lateinische übersetzen. Vgl. RaNkE, Jugenderinnerungen (wie Anm. 49), S. 39 f.

68 Noch in der Mitte des 19. Jahrhunderts wird an exponierter Stelle für den schulischen Zwang („befohlener Predigtbesuch“) zum Besuch des sonntäglichen Gottesdienstes plädiert, denn wabre Bildung und Teilnahme am Gottesdienst würden einander bedingen. Vgl. V. STrebel, Kirchenbesuch, in: Encyklopädie des gesammten Erziehungsund Unterrichtswesens, 4. Bd., Gotha 1865, S. 22-30. 
Über das Problem, den Übergang zwischen „normaler“ religiöser Erziehung und direkter pietistischer Einflussnahme deutlicher zu erfassen, wurde schon gesprochen, ebenso über die intensive Religiosität am Görlitzer Gymnasium unter Rektor Grosser: Häufige Betstunden, regelmäßige Teilnahme der gesamten Schülerschaft am Abendmahl, ständige Mahnungen zu einem sündenfreien und frommen Lebenswandel gehörten zum Schulalltag. Im benachbarten Lauban musste in jeder Woche ein Schüler eine Probepredigt halten, was der spätere Freidenker Edelmann kritisch vermerkte: Es sei alles geistlose Schwäzekunst gewesen. ${ }^{69}$ Ein spezielles Kapitel würde der Einfluss des sich im zweiten Drittel des Jahrhunderts entfaltenden Herrnhutertums bilden. In Schulen außerhalb der Oberlausitz muss wohl ein offenes Bekenntnis zur Herrenhutischen Secte eher die Ausnahme gebildet haben, denn ein solcher Schritt erregte unbedingt Aufsehen. In der Leipziger Thomasschule versuchte ein für das Herrnhutertum gewonnener Schüler seine Gefährten zu bekehren, was den Superintendenten auf den Plan rief. Im Gespräch behauptete der Schüler, 80 Personen, darunter Studenten, würden sich in Leipzig zur Secte bekennen. ${ }^{70}$ Die lutherische Amtskirche stellte sich entschieden gegen die Herrnhuter, und nur die Unterstützung durch die kurfürstliche Regierung sicherte die Existenz der neuen Glaubensbewegung. ${ }^{71}$ An den vom Oberkonsistorium kontrollierten Schulen dürfte sie kaum geduldet worden sein.

Es fällt nicht schwer, Stimmen zu sammeln, die dem Religionsunterricht und den religiösen Übungen einen eher formalen Charakter zuschreiben. Deren Einfluss auf die Persönlichkeitsbildung der Schüler wird entsprechend gering angesetzt. Lessings jüngerer Bruder Karl Gotthelf urteilte über Meißen: [...] wer mehr vom Studiren als vom Beten hielt, studirte obne zu beten. Freylich mußte er die Vorsicht gebrauchen, sich auf keiner solchen Sünde ertappen zu lassen. Es geschab auch selten [...].72 Aus einer pietistischen Richtung scheint die Kritik des späteren

69 Edelmann, Selbstbiographie (wie Anm. 47), S. $14 \mathrm{f}$.

70 Vgl. Gustav Wustmann, Auszüge aus Johann Salomon Riemers Leipzigisches Jahrbuche 1714-1771, in: Ders., Quellen zur Geschichte Leipzigs, 1. Bd., Leipzig 1889, S. 193-456, hier S. 243 f. Von der Meißner Fürstenschule wird ein Schüler verwiesen, der phanatische Bücher gelesen hatte. Vgl. DöRIng, Die Fürstenschule (wie Anm. 48), S. 94.

71 Die Herrnhuter scheinen sich überhaupt der Sympathie des Herrscherhauses erfreut zu haben. Als in Pyrmont der Leipziger Professor Ernst Platner 1791 einen Vortrag hält, der sich gegen die Andächtelei und deren Folgen wendet, kommentiert das die Schriftstellerin Elisa von der Recke: Wir erkannten an diesem Bilde der Regierung den gegenwärtigen Zustand von Sachsen, denn dies Land wird jetzt mebrenteils von Herrnhutern regiert. Diese Sekte verbreitet sich dort von Tage zu Tage mebr. Vgl. ELISA vON DER Recke, Tagebücher und Selbstzeugnisse, hrsg. von Christine Träger, Leipzig 1984, S. 127.

72 Vgl. G. E. Lessings Leben, nebst seinem noch übrigen litterarischen Nachlasse, 1. Theil, Berlin 1793, S. 31. Noch Jahrzehnte später ist es in Schulpforte nach der Erinnerung einer der Schüler nicht anders gewesen. Man habe die Bibel zur Andacht mitbringen müssen, um den zu behandelnden Abschnitt aufzuschlagen: Freilich geschab dies von Seiten Vieler nur ganz äußerlich und zum Scheine, obne daß sie mit irgend welcher Andacht dem verlesenen Abschnitt folgten. Vgl. Bernhard Rogge, Aus sieben Jahrzehnten. Erinnerungen aus meinem Leben, 1. Bd., Hannover/Berlin 1897, S. 71. Rogge besuchte 1843 bis 1850 Schulpforte. 
Pfarrers Deutschmann zu kommen: In religiöser Beziehung blieb ich jedoch in meiner Gymnasialzeit völlig geistlich tot. Unser Religionslebrer [...] war zwar ein bibelgläubiger orthodoxer Geistlicher, muß aber doch gänzlich obne Einfluß darin auf unser Gemüt gewesen sein [...].73 Vor den Gymnasien machten auch die um sich greifenden deistischen Strömungen keinen Halt. Die christliche Religion wurde hier auf einige Vernunftsätze und auf bloße Morallehren reduziert. Alles andere galt als zeitbedingt und damit eigentlich entbehrlich. Lehrer, die mit dieser Ideenwelt in Berührung gekommen waren, vermittelten sie innerhalb ihrer Schulen. Der spätere Mediziner Karl Burdach erlebte in der Person des Leipziger Nikolaischullehrers Gottlieb Samuel Forbiger einen erklärten Vertreter dieser Richtung: Er erklärte [...], daß viele Dogmen der Kirche spätere Zusätze sind, die dem Geiste der christlichen Religion zuwiderlaufen [...]. Die Dreieinigkeit, der Teufel, die Erbsünde und der Versöhnungstod gebörten nach Forbigers Lebre zu den vom wirklichen Christenthume zu unterscheidenden Dogmen. ${ }^{74}$

Wir wenden uns jetzt den Fächern zu, die an den Schulen im 18. Jahrhundert noch eine marginale Rolle spielten, die aber heute an den Gymnasien in der Regel die klassischen Sprachen an den Rand gedrängt haben. Das sind die modernen Sprachen, allen voran die deutsche Muttersprache, und die Naturwissenschaften einschließlich der Mathematik. Spielte neben der Erlernung der klassischen Sprachen die Beschäftigung mit der Muttersprache Deutsch zuvor überhaupt eine Rolle? Tatsache ist, dass von einem Großteil der Pädagogen Deutsch als Vulgärsprache für nicht unterrichtsrelevant gehalten wurde. Ich zitiere ausnahmsweise eine Stimme außerhalb Sachsens und zwar einen Lübecker Lehrer. Sein ihm vorgesetzter, im Zitat erwähnter Schulrektor, dem wir schon im Abschnitt über den Wolffinanismus an den Schulen begegnet sind, war jedoch zuvor Professor an der Leipziger Universität gewesen, sodass dessen Einstellung doch wohl auch ein Licht auf die sächsischen Verhältnisse wirft: Ich aber muß mich mit einer ungezogenen Jugend plagen, und noch darzu sebr oft vor einen deutschen Michel ausschelten lassen. Ja (im Vertranen) unser H. superintendens der berübmte Carpzov ist deswegen ein feind von mir, weil ich die deutsche Sprache liebe, und die Kühnheit gehabt, bey gewissen Umständen zu zeigen, daß die deutsche Sprache wobl so

MüLLER, Lebenserinnerungen (wie Anm. 49), S. 45.

Vgl. BuRDACH, Rückblick (wie Anm. 24), S. 40. In Schulpforte wurde der Religionsunterricht auf Grundlage der ganz rationalistisch orientierten „Epitome Theologiae Christianae“ des Leipziger Theologen Samuel Friedrich Nathanael Morus erteilt. Vgl. Ranke, Jugenderinnerungen (wie Anm. 49), S. 39 f. Noch in den zwanziger Jahren des 19. Jahrhunderts erklärte sich der Religionslehrer der Grimmaer Fürstenschule seinen Schülern gegenüber offen zum Rationalismus. Vgl. Koechly, Gottfried Hermann (wie Anm. 52), S. 111 f. Eine religionskritische Stimmung scheint um 1800 an nicht wenigen Schulen verbreitet gewesen zu sein. Ich verweise als Beispiel nur noch auf das bereits erwähnte Gymnasium zum Grauen Kloster in Berlin. Dort soll ein sehr freygeistiger Ton geherrscht haben, und der spätere Geistliche Wegener, von dem wir diesen Bericht haben, verliert dort über Nacht seinen bisher unerschütterten Glauben. Immerhin bleibt er Anhänger der natürlichen Religion. Vgl. Hermann, Leben und Werk (wie Anm. 55), S. $432 \mathrm{f}$. 
nothig sey, als die lateinische. ${ }^{75}$ Von einer Einsicht in diese Notwendigkeit war die Zeit noch weit entfernt. Einen wirklich eigenständigen nennenswerten deutschen Sprach- oder gar Literaturunterricht dürfte es bis in die zweite Hälfte des 18. Jahrhunderts an keiner sächsischen höheren Schule gegeben haben, auch wenn in diesen oder jenen Verordnungen von Übungen in deutscher Sprache die Rede ist. ${ }^{76}$ In den Fürstenschulen werden immerhin 1769 Deutschübungen eingeführt, wobei sich das besonders konservative Schulpforte erst sehr viel später dieser Reglung anschloss. ${ }^{77}$ Noch wichtiger war dann die oben erwähnte kursächsische Schulverordnung von 1773, die die Lektüre deutscher Schriftsteller und intensive Übungen zur Beherrschung des Deutschen zumindest formal bindend vorschrieb. Auch bei dieser Bestimmung stellt sich natürlich die Frage nach ihrer tatsächlichen Umsetzung. Noch in den achtziger Jahren soll durch Rektor Johann Friedrich Fischer an der Leipziger Thomasschule der Gebrauch der deutschen Sprache geradezu verboten worden sein: Selbst die deutsche Sprache verachtete er unbedingt; und vollends ein Gelebrter, der deutsch schrieb, war ibm ein Greuel. Hieraus folgte, das [...] von uns Allen durchaus kein Buch, das in deutscher oder sonst einer neuen Sprache geschrieben war, gelesen werden sollte [...].78 An der benachbarten Nikolaischule sah es kaum besser aus, auch wenn hier die Privatlektüre deutscher Texte kein Problem darstellte: Wir erbielten auch keinen Unterricht in der deutschen Sprache, sondern mußten die Gesetze derselben beim Lesen vaterländischer Schriftsteller entdecken, und wer Neigung dazu hatte, studirte nebenbei die deutsche Grammatik; solch freiwilliges Studium ist aber nicht selten erfolgreicher als ein genöthigtes. ${ }^{79}$

In den Jahrzehnten vor der Reform von 1773 hing viel von den einzelnen Lehrern ab, ob und wie der deutschen Sprache Raum im Unterricht gewährt wurde. In der Oberlausitz z. B. billigten die Rektoren Weise und Grosser Übungen in deutscher Sprache durchaus Bedeutung zu. Das Deutsche müsste, so Grosser, ebenso

75 Lange an Gottsched, 6. Dezember 1734, in: GotTsched, Briefwechsel, Bd. 3 (wie Anm. 38), S. 269-272.

76 So in den beiden Leipziger Gelehrtenschulen. Vgl. Töpfer, Die Freyheit (wie Anm. 2), S. 157-159.

77 Encyklopädisches Handbuch der Pädagogik (wie Anm. 5), S. 494. Leopold von Ranke besuchte zu Beginn des 19. Jahrhunderts die Schule. Von deutschen Autoren sei vor allem Klopstock, selbst ein Schüler der Pforte, gelesen worden, aber das ernstliche Studium gehörte ausschließend der alten Welt an. Vgl. RANke, Zur eigenen Lebensgeschichte (wie Anm. 63), S. 23. Tatsächlich ist in Rankes ausführlichen Aufzeichnungen über die Schulzeit fast allein von der Lektüre antiker Autoren die Rede. Selbst als sich die Frühjahrkämpfe von 1813 in der Nähe der Schule abspielten, betrachtet Ranke die Ereignisse als Wiederholung der Kämpfe zwischen Briten und Römern, denn er las gerade Tacitus'Agricola (S. 25 und an anderen Stellen der Erinnerungen). KNick, St. Thomas (wie Anm. 61), S. 242. Nach Rochlitz' Bericht soll Fischer auf das tiefste bedauert haben, dass sein Freund Lessing anfing auf Deutsch zu schreiben, obwohl er doch auf das vorzüglichste Latein und Griechisch beherrschte und daher ein großer Gelehrter hätte werden können (S. 249). 
sorgfältig wie das Lateinische und Griechische, ja bey manchen Subjectis auch noch sorgfältiger geübt werden. ${ }^{80}$ In der Praxis auch der Zittauer Schule bewahrten die alten Sprachen jedoch weiterhin ihre dominierende Position. Schulen von denen wir mit Sicherheit wissen, dass dort Deutsch Beachtung fand, sind Annaberg und Zwickau. Beide wurden (nacheinander) von dem schon erwähnten Christian Clodius geleitet. In Annaberg wird die Jugend insbesondere mit den Dichtungen des großen schlesischen Lyrikers Johann Günther vertraut gemacht; sie soll dessen Verse nachahmen, also ähnlich wie dies im Lateinunterricht im Umgang mit den antiken Autoren gehandhabt wurde. In Zwickau führte Clodius Gottscheds Lehrbuch „Kern der deutschen Sprachkunst“ ein. Nach Erscheinen der ersten Auflage bestellte er beim Autor zehn Exemplare. Fällt der Test des Buches in der Schule positiv aus, wolle er weitere Exemplare ordern. ${ }^{81}$ Aber auch bei dem Beispiel Clodius geben die Quellen eine ambivalente Auskunft. Sichtet man die Literaturtitel, die Clodius seinen Schülern zur Lektüre empfahl, stößt man fasst allein auf antike oder neulateinische Texte. Immerhin gelangte auch moderne deutsche Literatur in die berühmte Zwickauer Ratsschulbibliothek. So schenkte Gottlieb Wilhelm Rabener ein Exemplar seiner berühmten Satiren. Rektor Clodius dankt für das außnebmend fromme Buch, womit Sie einen guten Theil der Menschen erleuchten. In der Bibliothek reißt es einer dem andern aus der Hand. ${ }^{82}$ Ansonsten hing es natürlich auch von den Schülern selbst ab, inwieweit sie sich mit deutscher Literatur beschäftigten. Das gilt besonders für die Fürstenschulen, wo den Eleven ein relativ großer Zeitraum für das Selbststudium zur Verfügung stand. Bekannt sind Gellerts Aufzeichnungen über seine Lektüre in der Meißener Fürstenschule. Das Lesen von Günthers Gedichten habe ihn zu einem feuerspeienden Aetna gemacht, was ihm später allerdings peinlich war. ${ }^{83}$ Auch dem ersten Gellert-Biografen, Johann Andreas Cramer, ist die Wahl der nun vergeßnen Verse des schlesischen Dichters im Rückblick schwer verständlich, aber man müsse bedenken, dass unter den damaligen Gelehrten es fast für ein Verbrechen gehalten wurde, sich um seine Muttersprache zu bekümmern, und so habe Gellert eben nicht die rechte Beratung bei der Wahl seines Lesestoffes gefunden. ${ }^{84}$ Heute, wo Günthers Dichtungen fast als einziges ansprechendes deutsches Litera-

80 DörIng, Deutsche Gesellschaft (wie Anm. 30), S. 37.

81 Clodius an Gottsched, 29. März 1754 (Universitätsbibliothek Leipzig, Ms 0342 XIX, Bl. 152). Gottscheds Schulgrammatik fand zu ihrer Zeit weite Verbreitung. Vgl. HorsT Joachim Frank, Geschichte des Deutschunterrichtes. Von den Anfängen bis 1945, München 1973, S. 94-96.

82 Clodius an Rabener, 1. November 1755 (Universitätsbibliothek Leipzig, Autographensammlung Clodius).

83 Vgl. Christian Fürchtegott Gellert, Unvollständige Nachricht aus meinem Leben, in: Christian Fürchtegott Gellert, Gesammelte Schriften, hrsg. von Werner Jung/John F. Reynolds/Bernd Witte, Bd. 5, Berlin/New York 1994, S. 313-341, hier S. 314 .

84 Cramer, Gellerts Leben (wie Anm. 46), S. 186. 
turgut des frühen 18. Jahrhunderts gilt, also gerade nicht vergessen ist, mutet uns Cramers Urteil als sonderbar an.

Immerhin wurde in Meißen seit 1727 das Abfassen von deutschen Briefen unterrichtet, und es war gestattet, Reden auch in deutscher Sprache zu halten. In Meißen soll übrigens, wenn auch nur für kurze Zeit, eine „Deutsche Gesellschaft“ bestanden haben, an deren Spitze einer der Lehrer stand. Der Schulleitung war sie ein Dorn im Auge. ${ }^{85}$ Bekannter ist eine gleichnamige Sozietät, die um 1740 in Schulpforte existierte; Klopstock war ihr berühmtestes Mitglied. ${ }^{86}$

Der Beschäftigung mit der deutschen Sprache und Literatur eröffneten sich noch zwei andere Möglichkeiten, die heute ganz und gar weggefallen sind. So wurde die Befähigung zum Dichten, d. h. in erster Linie zum Verseschmieden an allen Schulen vermittelt. Sie galt als durchaus wichtiger Unterrichtsgegenstand, denn dieses Können bildete ein unbedingtes Muss im späteren Berufsleben. Stand auch hier das Dichten in lateinischer Sprache oben an, so besaß doch das Verfassen von Gedichten in der Muttersprache einen gewissen Platz in den Übungen der Schüler. Wie bei anderen Fächern war die Intensität, mit der das Poetisieren betrieben wurde, an den einzelnen Schulen unterschiedlich ausgeprägt. Das belegen u. a. Berichte von Zeitgenossen. So erinnerte sich der berühmt-berüchtigte Johann Christian Edelmann, der als Schüler aus Thüringen nach Lauban in der Oberlausitz kam, an seine dortigen Erlebnisse: sonderlich gab es treffliche Versmacher unter ibnen, gegen welche ich, der ich in Sangerhausen kaum geböret hatte, was Poesie war, gar nicht aufseben durfte. ${ }^{87}$

Eine andere Einfallspforte für den Gebrauch des Deutschen in der Schule bildete das Theater. Theateraufführungen nahmen vom 16. bis zum frühen 18. Jahrhundert eine wichtige Position innerhalb der Ausbildung ein. Dadurch sollten Sprach- und Körperbeherrschung geübt werden und zwar in einer für die Außenwelt sichtbaren Form. Schon die Tatsache, dass die Aufführungen öffentlichen Charakter trugen, erforderte zwar nicht zwangsläufig, aber doch verstärkt den Gebrauch des Deutschen. Aufgeführt werden in erster Linie Stücke biblischer oder antiker Stoffwahl, aber es fehlt auch nicht an Texten zur Geschichte oder gar zum Zeitgeschehen. So kommt 1684 in Görlitz ein Stück „Wien in Leid und Wien in Freud“ auf die Bühne, das natürlich von der Belagerung Wiens im Jahr zuvor handelt. ${ }^{88}$ Gut zwanzig Jahre später gelangte ein Stück über die gerade erfolgte schwere Niederlage der sächsischen Truppen gegen die Schweden in der Schlacht

85 Vgl. Döring, Die Fürstenschule in Meißen (wie Anm. 48), S. 106.

86 Vgl. Hermann Peter, Die Pflege der deutschen Poesie auf den sächsischen Fürstenschulen im zweiten Viertel des vorigen Jahrhunderts, in: Mitteilungen des Vereins für Geschichte der Stadt Meissen 1 (1884), H. 3, S. 23-69, zu Schulpforte vor allem S. 48-67. Die Organisation und Arbeitsweise dieser Schülergesellschaft ähnelte ganz dem Leipziger Vorbild, wie auch Gottscheds Gedichte als poetische Anleitung dienten. Sogar seine Rechtschreibung galt als verbindlich.

87 Edelmann, Selbstbiographie (wie Anm. 47), S. 13.

88 Vgl. Döring, Katalog der Handschriften (wie Anm. 59), Neue Folge I/2, S. 5. 
bei Fraustadt zur Aufführung. ${ }^{89}$ Verfasser der Bühnentexte waren in nicht wenigen Fällen die Lehrer selbst. In der ersten Hälfte des Aufklärungsjahrhunderts gerät das Schultheater allerdings immer massiver unter den Druck seiner Kritiker. Es sind zwar nicht allein die Theologen, an ihrer Spitze die Pietisten, die das Theater vehement ablehnen, aber sie üben immer noch einen besonders großen Einfluss aus. Schon 1718 wurde das Schultheater in Preußen, wo der Pietismus wachsenden Einfluss gewann, schlechterdings verboten; bereits in den Jahren zuvor war es kaum noch zu Aufführungen gekommen. Das Schauspiel, so die Klage der Theologen, lenke die Schüler vom Lernen ab, würde eine „ungesunde Phantasie“ erzeugen, und überhaupt sei das Komödiantenwesen verwerflich, heidnisch und damit gottlos. ${ }^{90}$ Schließlich verleite es zu Müßiggang und zu sinnlosen Geldausgaben. Unter diesen Angriffen und durch direkte Verbote verschwand das Theaterspielen immer mehr aus den Schulen. Das gilt auch für Sachsen. 1744 kommt es an der Grimmaer Fürstenschule letztmalig zu einer Theateraufführung. Einer der letzten, die noch mit schwindender Kraft um den Fortbestand des Theaters kämpfen, ist der schon erwähnte Zwickauer Rektor Christian Clodius. Das Theater, so sein Argument, sei keine sinnlose Zeitverschwendung, sondern komme dem Schüler für sein späteres Berufsleben zugute: Es stehen bereits über 10. von meinen vormaligen Scholaren auf den Cantzeln, und thun alle mebr, als andere, die nur hinter einem alten wurmstichigen bestaubten Kasten gestanden [...] obne einen Geschmack von der künstlichen und natürlichen Freymüthigkeit im Reden gefaßt zu haben. ${ }^{91}$ Der herrschende Zeitgeist stand jedoch solchen Auffassungen entgegen, und so fand das Schultheater sein Ende.

Der Musikunterricht spielte an den meisten Schulen, also nicht allein an der Leipziger Thomasschule mit ihrem berühmten Chor, eine gewisse Rolle, waren

89 DöRIng, Katalog der Handschriften (wie Anm. 59), S. 13. Vgl. auch Max Gondolatsch, Beiträge zur Görlitzer Theatergeschichte bis 1800, in: Neues Lausitzisches Magazin 103 (1927), S. 107-164; und Kretzschmar, Schulbildung in Görlitz (wie Anm. 12), S. 31-34.

90 Vgl. Wolfgang Martens, Officinia Diaboli. Das Theater im Visier des halleschen Pietismus, in: Norbert Hinske (Hg.), Halle. Aufklärung und Pietismus, Heidelberg 1989, S. 183-208. Noch in der Mitte des 19. Jahrhunderts übte der Theologe Christian Palmer schärfste Kritik am Theaterspiel der Jugendlichen. Dadurch würde eine Leidenschaftlichkeit erregt, die die Kinder voll und ganz vereinnahmen würde. Außerdem würden alle Untugenden des Theatervolkes vermittelt. Vgl. Christian Palmer, Evangelische Pädagogik, Stuttgart 1855, S. 195. Die oben mitgeteilten Daten zum Verbot des Schultheaters sind diesem Werk entnommen worden.

91 Clodius an Gottsched, 3. Dezember 1754 (Universitätsbibliothek Leipzig, Ms 0342, XIX, Bl. 570). Gottsched wird immer wieder von Gymnasiallehrern um Hilfe bei der Suche nach geeigneten Stücken gefragt, so z. B. von Johann Balthasar Schmidt aus Schmalkalden: Bey der biesign Schule ist es bräuchlich, daß die Schüler im Sommer eine Comödie oder Tragödie spielen, sollte Ew. Magnificenz [...] etwas schönes, und der Jugend wobl anständiges im Druck bekannt seyn, so wollte mir davon entweder einige Nachricht, oder das Exemplar selbsten vor die Bezablung ausgebeten haben. Brief vom 1. Mai 1735. Vgl. Gottsched, Briefwechsel, Bd. 3 (wie Anm. 38), S. 363 f. 
doch die von den Schülern geforderten liturgischen Dienstleistungen bei religiösen Handlungen eine der wesentlichen Ursachen für die Gründung von Schulen im Mittelalter gewesen. Bei Luther besaß die Musik bekanntlich einen hohen Stellenwert, sie diente dem Lob Gottes und der Verbreitung seines Wortes. Auch in der Frühen Neuzeit blieben Dienstleistungen der Schulmusik gefragt, z. B. bei Trauerfeierlichkeiten. Der Musikunterricht stellte daher weiterhin eine feste Größe dar. Am Naumburger Domgymnasium wurde Montag bis Freitag täglich eine Stunde Musikunterricht erteilt. ${ }^{92}$ Die Laubaner Schulordnung legte fest, dass Musik täglich publice und privatim zu üben sei, denn sie sei eine edle Gabe Gottes. ${ }^{93}$ Einer der nicht wenigen erfolgreichen Schulkantoren ist Johann Christoph Urban aus Görlitz. Schon dort kommt er mit der Musik in Berührung, in Leipzig ist er später Opernsänger, vor allem aber Schüler des Thomaskantors Johann Schelle. Das Amt des Schulkantors übt er dann zuerst in Torgau aus, ${ }^{94}$ immerhin 17 Jahre lang, um dann in seine Heimatstadt zurückzukehren, wo er bis zu seinem Lebensende Kantor am Gymnasium blieb. In Görlitz werden die Aufführungen des Schultheaters oft musikalisch begleitet. Das Gymnasium unterhielt sogar einen Chor (Chorus symphoniacus), der auch außerhalb der Schule in Aktion trat. ${ }^{95}$ So erfolgte 1688 auf der „Görlitzischen Schaubühne“ ein von der Studirenden Jugend aufgeführtes Musicalisches Traner- und Freuden-Spiel mit dem Titel „Jesus in Leiden/ Jesus in Freuden“. ${ }^{96} \mathrm{Ob}$ im Verlaufe des 18. Jahrhunderts die Bedeutung des Musikunterrichtes in der Schule das frühere hohe Niveau bewahren konnte, ist unsicher. Ähnlich wie beim Theater mag dabei der Pietismus eine Rolle gespielt haben, denn auch die Musik wurde von ihm als eine eher gottferne Angelegenheit mit Misstrauen betrachtet. ${ }^{97}$ Zumindest gilt das für bestimmte Formen der Musik, z. B. für die Kunstmusik in den Kirchen. ${ }^{98}$

92 Ernst-Joachim Meusel, Das Domgymnasium zu Naumburg, in: Gymnasien der Provinz Sachsen (wie Anm. 3), S. 46-54, hier S. 52 (Stundenplan aus dem Jahre 1667).

93 Vgl. Gottrried Hoffmann, Ausführlicher Bericht von der Methode oder Lehr-Art welche bey denen verordneten Lectionibus im Laubanischen Lyceo gehalten werden, Lauban o. J., S. 36.

94 Vgl. Osкar Böнm, Chronik der Oberschule Torgau (Kleine Schriften des Torgauer Geschichtsvereins 12), Torgau 1999, S. 71. Der Verfasser vermittelt auf den S. 66-78 weitere Informationen über das Musikleben am Torgauer Gymnasium.

95 Vgl. Max Gondolatsch, Görlitzer Musikleben in vergangenen Zeiten, Görlitz 1914, zur Musik an der Schule S. 27-35.

96 Universitätsbibliothek Leipzig, Ms 0307 (II), Bl. 163 f. (Einladungsschrift).

97 Vgl. Martens, Officinia Diaboli (wie Anm. 90), S. 197-199.

98 Vgl. Christian Bunners, Musik, in: Lehmann, Geschichte des Pietismus (wie Anm. 28), 4. Bd., S. 428-455. Der Autor bemüht sich um eine Aufwertung der Bedeutung des Pietismus für die Musikgeschichte. Eine wesentliche Rolle spielt der Pietismus auf jeden Fall in der Entwicklung des Liedes bzw. des Gesanges. Vgl. Gudrun Busch/Wolfgang Miersemann (Hg.), „Geist=reicher“ Gesang. Halle und das pietistische Lied, Halle/ Tübingen 1997. 
Von noch nachhaltigerer Wirkung war vielleicht das allmähliche Verschwinden der kirchlich-gottesdienstlichen Traditionen, die bislang eine liturgisch-funktional begründete Musikerziehung an den Schulen erfordert hatten. ${ }^{99}$ Im Vergleich zu den jetzt aufkommenden, ein stärkeres Gewicht erlangenden Fächern verlor so der Musikunterricht schrittweise an seiner öffentlich empfundenen Notwendigkeit. So beklagen verschiedene mit dem Musikwesen an einzelnen Schulen vertraute Zeitgenossen einen doch signifikanten Rückgang der Wertschätzung der Musik. Der Schulkantor Kauderbach in Meißen konstatiert nach fast fünfzigjähriger Tätigkeit: So hätten die binnen meiner Zeit eingefübrten Maitres in Mathematischen Wißenschafften, französischer und italienischer Sprache, Tanzen und Calligraphie denen Lehrlingen theils die Zeit geraubet theils ein degout vor vocal und instrumental Music erweckt. Überhaupt besäßen die Schüler kaum noch Lust an Musik und Gesang. ${ }^{100}$ Auch war der Kantor fast nie allein nur für den Musikunterricht zuständig. Oft genug musste er, wie wir das auch von Bach wissen, in noch ganz anderen Fächern in Erscheinung treten. ${ }^{101}$ An der Leipziger Nikolaischule, die in dieser Hinsicht freilich ganz im Schatten der benachbarten Thomasschule stand, scheint um 1800 der Musikunterricht nur noch in einer Schwundstufe vermittelt worden zu sein: An dem dürftigen Unterrichte im Singen nabmen die obern Classen keinen Theil, und ich hatte, als ich in diese anfgerückt war, auch den Privatunterricht im Claviere schon abgethan, da ich wenig Talent dafür bewiesen und die Lust dazu bald verloren hatte, woran der Lebrer wohl auch einige Schuld haben mochte. ${ }^{102}$ Aber auch das sind wiederum Einzeläußerungen, die nicht ohne weiteres verallgemeinert werden können. ${ }^{103}$

Besaß das Fach Deutsch lange Zeit nur mäßige Chancen, in den Unterricht als offizielles Fach Einzug zu halten, so konnten sich einige Realienfächer an den

99 Vgl. Christoph Richter/Karl Heinrich Ehrenforth/Ulrich Mahlert, Artikel: Musikpädagogik, in: Die Musik in Geschichte und Gegenwart, Sachteil, Bd. 6 (1997), S. 1439-1534; zum Musikunterricht in der Frühen Neuzeit vgl. S. 1483-1491).

100 Vgl. Döring, Die Fürstenschule in Meißen (wie Anm. 48), S. 106 f.

101 Der erwähnte Meißner Kantor Kauderbach muss auch Kirchengeschichte, Geografie und Genealogie unterrichten. Vgl. DörIng, Die Fürstenschule in Meißen (wie Anm. 48), S. 106 f. Der Eislebener Kantor Matthäi unterrichtete Griechisch. Vgl. Johann Gottlieb Burckhardts Lebensbeschreibung (wie Anm. 53).

102 Burdach, Rückblick (wie Anm. 24), S. 38. Als in den zwanziger Jahren des 18. Jahrhunderts in Meißen über die Einführung der Mathematik als Unterrichtsfach diskutiert wurde, hieß es ausdrücklich, dadurch dürften die studia fundamentalia in bonis literis et linguis nicht beeinträchtigt werden. Überhaupt sollten nur diejenigen Schüler in Mathematik unterrichtet werden, die dazu hinreichend befähigt seien. Vgl. HStA Dresden, Loc. 1827, Acta die Einführung der Information in Mathesi bey der Chur-Fürstl. Sächs. Landschule Meißens betr. 1720-1729.

103 An der Grimmaer Fürstenschule z. B. soll im gesamten 18. Jahrhundert die Pflege der Musik in gleichbleibender Intensität betrieben worden sein, so das Urteil des ausgewiesenen Kenners Wolfgang Steude, Kantorat, Kantoren und Musikrepertoire der Fürstenschule zu Grimma, in: Flöter/Wartenberg, Von der kurfürstlichen Landesschule (wie Anm. 5), S. 87-94. 
Schulen wenigstens allmählich und auf einem eher bescheidenen Niveau durchsetzen. Dabei liegt die Betonung auf allmählich. Noch 1759 klagt der gerade in sein Amt eingeführte Leipziger Nikolaischulrektor Reiske, also ein ausgesprochener Philologe, darüber, dass in der Prima kein Unterricht in der Geometrie, Philosophie, Logik und Naturlehre erfolge. ${ }^{104}$

Der an den heutigen Schulen zumeist ganz zentrale Mathematikunterricht wurde an den Gymnasien bis ins 18. Jahrhundert als absolutes Nebenfach gehandelt, mit ein oder bestenfalls zwei Unterrichtsstunden in der Woche. ${ }^{105}$ In der angesehenen Zwickauer Ratsschule beispielsweise wurde Montag und Donnerstag jeweils eine Stunde Mathematik unterrichtet - für sämtliche Klassen zusammen. ${ }^{106}$ Mit der Zeit aber wurde die Vermittlung eines hinreichenden Wissens in der Mathematik und in den Naturwissenschaften angesichts der sich anbahnenden wissenschaftlichen, ökonomischen, technischen und allgemeinen kulturellen Wandlungsprozesse immer stärker als eine Notwendigkeit empfunden. So öffneten sich, wenn auch zögernd, die Universitäten als höchste Bildungsanstalten wenigstens einigen dieser Erfordernissen, so dem Erlernen moderner Sprachen, dem ingenieurtechnischen Wissen und den Kameralwissenschaften. Auch die Gründung von Ritterakademien im ausgehenden 17. und beginnenden 18. Jahrhundert ist in diesem Zusammenhang zu sehen. Sachsen hatte sich mit der 1692 erfolgten Einrichtung einer Ritterakademie in Dresden dieser Tendenz angeschlossen. ${ }^{107}$ Ein Vorbild waren auch die in Halle von August Hermann Francke um 1700 betriebenen Schulgründungen, die bei aller bleibenden Schwerpunktsetzung bei den alten Sprachen doch auch den "modernen Fächern“ einen beträchtlichen Raum zugestanden. In Görlitz sprach bereits 1695, also noch vor den Gründungen in Halle, Rektor Grosser von einer „nova schola“, die u. a. Wissen in den Fächern Mathematik, Geografie und Geschichte vermittelt. ${ }^{108}$ In Kursachsen wird für die Fürstenschulen 1728 eine Reform verordnet, die u. a. einigen neuen Fächern zumindest etwas mehr Platz im Unterricht gewährt. Das betraf z. B. Mathematik, Geografie, Geschichte, das Jus naturae und die modernen Sprachen.

Einen überwältigenden Siegeszug haben diese Disziplinen trotz aller Bemühungen nicht unbedingt anzutreten vermocht. Konservative Einstellungen blieben lange Zeit mächtig. Als z. B. im Gefolge der Schulreform von 1728 im folgenden Jahr auf Anordnung des Landesherrn ein Mathematiklehrer in Meißen eingeführt werden soll, regt sich vehementer Widerstand der Herren Kollegen, zum Teil mit

104 Johann Jakob Reiske an Jacob Heinrich Born, 28. Mai 1759. Stadtarchiv Leipzig (ehemals Archiv der Nikolaischule), NiS 347, S. 1-7, foliiert, korrigierter Entwurf. Der Brief ist in der von Richard Förster besorgten Ausgabe der Briefe Reiskes nicht enthalten. Ich verdanke Herrn Dr. Thomas Töpfer den Hinweis auf dieses Aktenstück.

$105 \mathrm{Vgl}$. Knut Radbruch, Didaktik der Mathematik im deutschen Barock, in: MorgenGlantz 12 (2002), S. 81-100.

106 Beck, Die Zwickauer Schule (wie Anm. 15), S. 122.

107 Vgl. Gross/John, Geschichte der Stadt Dresden (wie Anm. 13), Bd. 2, S. 49 f.

108 Salomon Grosser, Oratio de Flore Scholarum, Görlitz [1695]. 
heute als kurios anmutenden Argumenten: Der vorgesehene Lehrer, Johann Albert Klimm, sei kein Theologe und sei daher nicht in der Lage, Bibelstunden zu halten. ${ }^{109}$ Diese Fähigkeit aber wurde jedem Lehrer als zentrales Können abverlangt. Nach Mitteilung des Merseburger Schulrektors Thieme waren dort noch Ende des 18. Jahrhunderts Naturkenntnis, Geografie und Mathematik ganz unbekannte Dinge. Als Thieme auf die Berücksichtigung dieser Fächer drängte, wurde ihm seitens seiner Kritiker entgegengehalten, er wolle die alte solide Art zu studieren abschaffen und dagegen die Realiensucht einfübren. ${ }^{110}$ In Grimma gilt noch einhundert Jahre später Mathematik nicht als eigentlich gleichwertiges Fach; man konnte es gut und gern auch entbehren: Von Algebra haben wir während jenes Zeitraums kein Sterbenswörtchen vernommen, und in der Geometrie sind wir nur bis zum pythagoreischen Lehrsatze gekommen. Ein, guter Mathematiker' zu sein, galt uns als ein sebr zweifelhaftes Lob. ${ }^{111}$ Dieses Bild, das die weitgehende Abwesenheit der Realienfächer suggeriert, dürfte allerdings eine gewisse Korrektur erfordern, denn an manchen Schulen scheint ein privat gehaltener Unterricht interessierte Schüler mit Lehrinhalten vertraut gemacht zu haben, die im offiziellen Lehrplan nur schwach oder überhaupt nicht vertreten waren. Wir hörten davon bereits bei der Erwähnung des Geschichtsunterrichtes. Rektor Grosser in Görlitz z. B. hielt Collegia privata, in denen Geschichte, Geografie und Philosophie unterrichtet wurde. ${ }^{12}$ Der Mathematiklehrer Klimm in Meißen erteilte in seiner eigenen Stube Unterricht, der ein Wissen vermittelte, das über den Stoff hinausging, der im Schulzimmer erläutert worden war.

Dennoch dürfte es auch in den folgenden Jahrzehnten bei der Marginalisierung des Faches Mathematik im allgemeinen Unterricht geblieben sein. Das wurde von den Betroffenen, also von den Schülern, nicht unbedingt als sonderlicher Nachteil empfunden. Das belegt schon die eben zitierte Erinnerung Koechlys über Grimma. Für die Leipziger Verhältnisse urteilte der spätere Mediziner Burdach ganz ähnlich: Daß man auf meiner Schule nur in den untern Classen Rechnen lebrte und gar kein öffentlicher Unterricht in der Mathematik ertheilt wurde, war freilich zu tadeln, und doch kein großer Schaden. Die, welche Neigung zu diesem Studium batten, nabmen Privatstunden bei dem Cantor Bebringer [...].113

109 Vgl. Döring, Die Fürstenschule in Meißen (wie Anm. 48), S. 98 f. In Schulpforte erklärte der Mathematiklehrer Schmidt den Schülern die im Abendgebet behandelten alttestamentlichen Texte. Vgl. Ranke, Jugenderinnerungen (wie Anm. 49), S. 39.

110 Fertig, Bildungsgang (wie Anm. 19), S. 53.

111 Koechly, Gottfried Hermann (wie Anm. 52), S. 110.

112 Döring, Deutsche Gesellschaft (wie Anm. 30), S. 33 f.

113 BuRDACH, Rückblick (wie Anm. 24), S. 36. Ein anderer Nikolaischüler stellte im Rückblick dem eben erwähnten Mathematiklehrer jedoch eine eher schlechte Beurteilung aus: Der Quartus, M. Bebringer, gewann uns für seine Wissenschaft ebensowenig. Ich erinnere mich, als ich ibn einmal fragte, was doch die Wörter: Parabel, Hyperbel u.s.w, bedeuteten, daß er mir ganz naiv zur Antwort gab: „ja, Monsieur Weiß, darüber habe ich noch nicht nachgedacht." Vgl. Memoiren von Christian Weiss (wie Anm. 62). 
Abschließend sei festgehalten, dass ein auch nur einigermaßen eindeutiges Bild über die Unterrichtsinhalte und die Unterrichtsmethoden an den sächsischen höheren Schulen sich auf der Grundlage des heutigen Wissensstandes kaum gewinnen lässt. Es scheint eine komplizierte Gemengelage geherrscht zu haben, in der die Lateinschule des alten, der Reformationszeit verhafteten Stils noch überall gegenwärtig war, in der aber auch die einsetzende Reformbewegung des Neuhumanismus und die Einbeziehung moderner Fächer, d. h. Realienkunde, Geschichte und moderne Sprachen, wachsenden Raum erlangten. Das sind Entwicklungen, die sich über die Jahrzehnte hinziehen, regional und lokal ganz verschiedene Ausprägungen finden und selten schon einen eindeutigen Charakter tragen. 